\title{
High Temperature Sintering and Oxidation Behavior in Plasma Sprayed TBCs [Single Splat Studies] Paper 2-Relevance of Variation in Materials Systems of TBC Components
}

\author{
Swarnima Deshpande \\ Center for Thermal Spray Research, Department of Materials Science and Engineering, State University of New York at Stony Brook, \\ New York, USA. \\ Email: swarnima_d@yahoo.com
}

Received December $1^{\text {st }}, 2012$; revised January $3^{\text {rd }}, 2013$; accepted January $11^{\text {th }}, 2013$

\begin{abstract}
The TBC system's response to thermal exposure at high temperature is discussed here. The relevance of the microstructural aspects of each component of the TBC system is emphasized. The top coat is a YSZ ceramic coating consisting of a collection of splats on top of one another. The most important aspect of this layer is the inherent inter-splat and intra-splat porosity which undergoes sintering during thermal exposure. This study investigates the effect of thermal exposure on the microstructure and sintering behavior in single splats produced using different starting powders since this has been shown to influence the basic microstructure of YSZ topcoat. The bond coat is an MCrAlY metallic coating which serves as an Al reservoir and allows the formation of a protective alumina, Thermally Grown Oxide (TGO) layer between the bond coat (BC) and the top coat (TC) layers. This oxide scale formed upon thermal exposure prevents further oxidation of the underlying component (substrate) and thus provides protection. As such, the content of free Al in the bond coat layer is of significance and makes it crucial to understand the influence of bond coat microstructure evolution and oxidation involved during its formation. The interaction between the bond coat, the TGO and the top coat layers is examined in this study to understand the high temperature behavior of the TBC system with regards to variations in the top coat and bond coat material systems used.
\end{abstract}

Keywords: TBC; HVOF Bond Coat; Top Coat; Thermal Exposure; Vacuum Environment; Oxidation; TGO Imperfections; Sintering; Microcracks

\section{Introduction}

This study seeks to look into the influence of different material systems used for TBC system components. Different YSZ powders can be used to spray the topcoat and a variety of spray methods can be used to generate the bond coats. Previous study involving thermal exposure using single splats has indicated that the microcracks in these splats provide a path for the oxygen to reach the aluminum depleted areas in the underlying bond coat [1st paper, JSEMAT 2013]. Hence it was thought necessary to examine the TGO formation and interactions with YSZ during thermal exposure as a function of the initial YSZ splat layer and the as-sprayed bond coat microstructures.

High temperature and thermal cycling behavior of TBC systems has been a subject of great interest. When a TBC system is thermally exposed, it is transparent to oxygen because of the abundance of oxygen ion vacancies in $\mathrm{ZrO}_{2}$ and hence oxygen ingresses through the
YSZ top coat. The bond coat undergoes oxidation and leads to the formation of Thermally Grown Oxide (TGO). This bond coat is typically an MCrAlY alloy, designed as a local Al reservoir, enabling $\alpha$-alumina to form in preference to other oxides. The TBC Alumina is preferably formed because of its low oxygen diffusivity and superior adherence [1]. The thickness of TGO increases with thermal exposure and induces the strain energy for the crack propagation during spallation [2].

After exposure the TGO has a convoluted morphology with major imperfections, the most prominent being the undulations of the original TBC/bond-coat interface. This is outlined by the dark gray TGO layer. The thicker areas of TGO are predominantly $\alpha$-alumina containing veins of yttrium aluminates. Other oxides occur in isolated domains within the TBC next to the TGO and have a lighter gray contrast. These are typically spinels comprising oxides of $\mathrm{Cr} / \mathrm{Ni} / \mathrm{Co}$ often with associated internal porosity 
and these spinels when formed act as preferential sites for failure [3].

Shillington and Clarke studied the Changes in TGO during Oxidation [3]. Pieces of the same bond-coat alloy were oxidized for different times $(64,128,256,384$, 512 and $640 \mathrm{~h}$ ) at $1121^{\circ} \mathrm{C}$. It was seen that after $128 \mathrm{~h}$, the only phase detectable was $\alpha$-alumina. After $256 \mathrm{~h}$, the first indications of the formation of spinel and $\alpha$-chromia were detected. Alumina was no longer continuous after $384 \mathrm{~h}$ and the oxide was principally a mixture of spinel and $\alpha$-chromia. Alumina was no longer detectable after $512 \mathrm{~h}$.

Other studies have indicated that differences in the YSZ powder used generate differences in splat morphologies and porosity content of the TBC topcoat [4-6]. Also, bond coats $(\mathrm{NiAl})$ sprayed by different processes have been extensively examined to understand the oxidation involved during spraying and its influence on microstructural evolution. It has been shown that Air plasma spraying and Wire arc spraying involve different mechanisms of oxidation during the entire spray process and generate coatings with a much higher oxide content compared to HVOF spray process [7]. This study aims to examine the effect of these variations in the component material systems on the behavior of the TBC system upon subsequent thermal exposure.

\section{Experimental Approach}

Single splats of YSZ were collected on NiCrAlY/ CoNiCrAlY bondcoat surfaces in order to conduct thermal exposure studies on the same. For the first set of coatings, NiCrAlY coatings were air plasma sprayed onto Inconel 718 superalloy substrates. Processing conditions for the same are tabulated below in Table 1.

Zirconia powders with different powder morphologies were used to spray splats onto the polished surfaces of these MCrAlY bond coats using APS process with spray parameters as indicated in Table 2. The PSZ powders

Table 1. Deposition parameters for APS sprayed NiCrAIY Bond coat.

\begin{tabular}{cc}
\hline Gun & Sulzer F4MB \\
\hline Gun voltage & $68 \mathrm{~V}$ \\
Gun current & $500 \mathrm{~A}$ \\
Primary gas (Ar) & $50 \mathrm{SLPM}$ \\
Secondary gas $\left(\mathrm{H}_{2}\right)$ & $10 \mathrm{SLPM}$ \\
Carrier gas (Ar) & $3 \mathrm{SLPM}$ \\
Spray distance & $120 \mathrm{~mm}$ \\
Powder Feed rate & $40 \mathrm{~g} / \mathrm{min}$ \\
\hline
\end{tabular}

Table 2. Deposition parameters for APS sprayed YSZ splats.

\begin{tabular}{cc}
\hline Gun & PT-F4MB \\
\hline Gun voltage & $65 \mathrm{~V}$ \\
Gun current & $650 \mathrm{~A}$ \\
Primary gas (Ar) & $40 \mathrm{SLPM}$ \\
Secondary gas $\left(\mathrm{H}_{2}\right)$ & $8 \mathrm{SLPM}$ \\
Carrier gas (Ar) & $3 \mathrm{SLPM}$ \\
Spray distance & $100 \mathrm{~mm}$ \\
Powder Feed rate & $10 \mathrm{~g} / \mathrm{min}$ \\
Gun traverse speed & $10 \mathrm{~mm} / \mathrm{sec}$ \\
Substrate rotational speed & $160 \mathrm{rpm}$ \\
\hline
\end{tabular}

used were:

1. Fused and Crushed Zirconia \& 2. HOSP Zirconia (Plasma-Densified Hollow Spheres).

For the second set of coatings, splats were collected on polished surfaces of HVOF and VPS sprayed CoNiCrAlY bond coats obtained from Engelhard Surface Technologies to analyze the effect of the bond coat system.

Thermal exposure behavior of these splats in air was studied using a Thermolyne 47,900 box furnace. The splats were isothermally exposed in Air at $1100^{\circ} \mathrm{C}$ for 8 $\mathrm{hr}$ and $24 \mathrm{hrs}$ to see the effect of duration. Also, thermal exposure was studied in vacuum to eliminate effect of bond coat oxidation. For this purpose, the samples were sealed in quartz tubes prior to treatment, up to a vacuum of $10^{-5}$ torr. This set of samples was subjected to an intermediate vacuum heat treatment at $1100^{\circ} \mathrm{C}$ for $2 \mathrm{hr}$ followed by a subsequent isothermal exposure in Air at $1100^{\circ} \mathrm{C}$ for $24 \mathrm{hr}$.

Particular splats were identified and the microcrack network, surface roughness, and splat lifting/spalling before and after HT were compared. SEM Back-scattered imaging (Leo 1550, FEG) was employed on splat crosssections to observe the splat dimensions, microcrack sintering and effect of TGO growth after HT. Energy Dispersive Spectrometry (EDS) gave elemental composition. Atomic Force Microscopy (AFM) was employed to quantify surface roughness of splats.

\section{Results and Discussion}

The thermal exposure studies were conducted using single splats on bond coat. Single splats as opposed to freestanding coatings include the splat/substrate interfacial interaction. Absence of thick top coat minimizes the factors introduced by TBC coating and behavior can be more related to the bond-coat chemistry and microstructure. Only isothermal heat treatments were carried out in order 
to eliminate cyclic TGO elongation effects.

\subsection{Effect of Variation in YSZ Top Coat Microstructure}

Changing the feedstock translates into changes in the assprayed splat dimensions which in turn have a distinct effect on the top coat structure. Different morphology YSZ powders, Fused and Crushed (FC) and Plasma Densified Hollow Spheres (HOSP) when sprayed through the plasma exhibit different flow behavior and different melting efficiencies and form splats with different dimensions.

Cross-section images of splats in Figure 1, show the diameters and thicknesses for FC and HOSP splats. Microcrack widths in each case are also measured. It can be noted that the FC zirconia splats are approximately 1.75 times thicker compared to HOSP splats. This is further addressed in the following section.
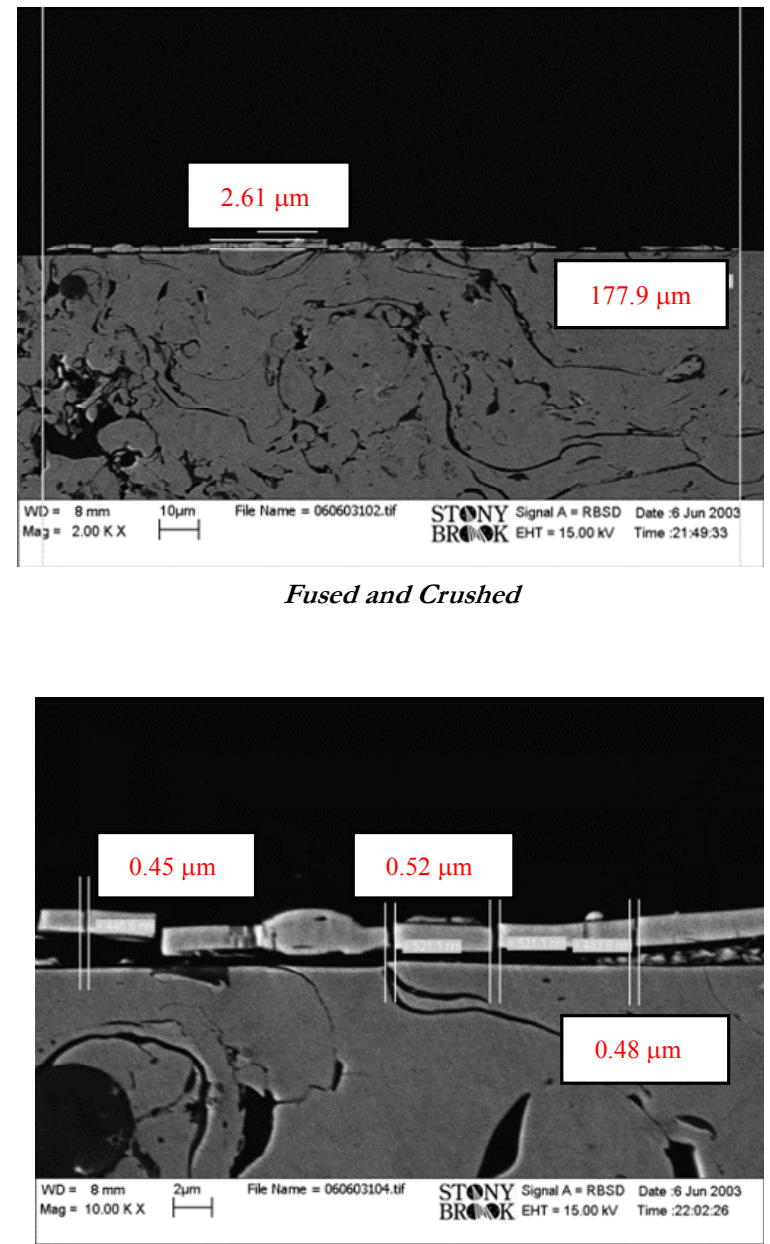

Fused and Crushed

\subsubsection{Splat Interfaces in Coating}

The number of interfaces in a coating is directly related to the thicknesses of individual splats which in turn are affected by flattening and spreading. Composite SEM cross-sectional images of coatings for both powder morphologies were used to observe the splat interfaces as shown in Figures 2(a) and (b). Several visible splat boundaries in these cross-sections are marked and splat thicknesses are noted for each of these splats. Then all these splat thickness values are used to compute the average splat thickness for each case.

The average splat thickness for FC YSZ coating averaged over 13 values was $4.14 \mu \mathrm{m}$ and that calculated for HOSP YSZ coating using 18 different values was 2.46 $\mu \mathrm{m}$. Thus it is once again seen that fused and crushed YSZ powders produced coatings with splats 1.7 times thicker than in the case of HOSP YSZ. Hence it was inferred that within a given thickness of say $250 \mu \mathrm{m}$, the average number of interfaces created by HOSP coating

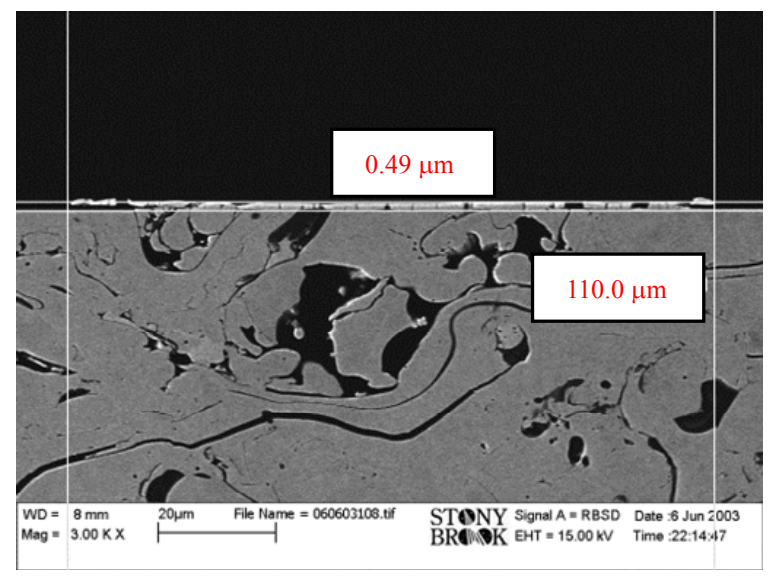

HOSP

(a)

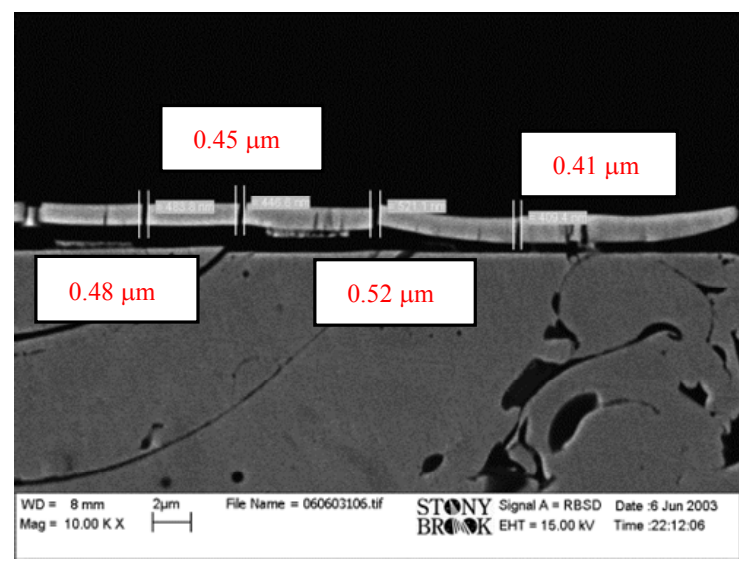

HOSP

(b)

Figure 1. (a) Cross-sections showing splat dimensions; (b) Cross-sections showing microcrack widths. 


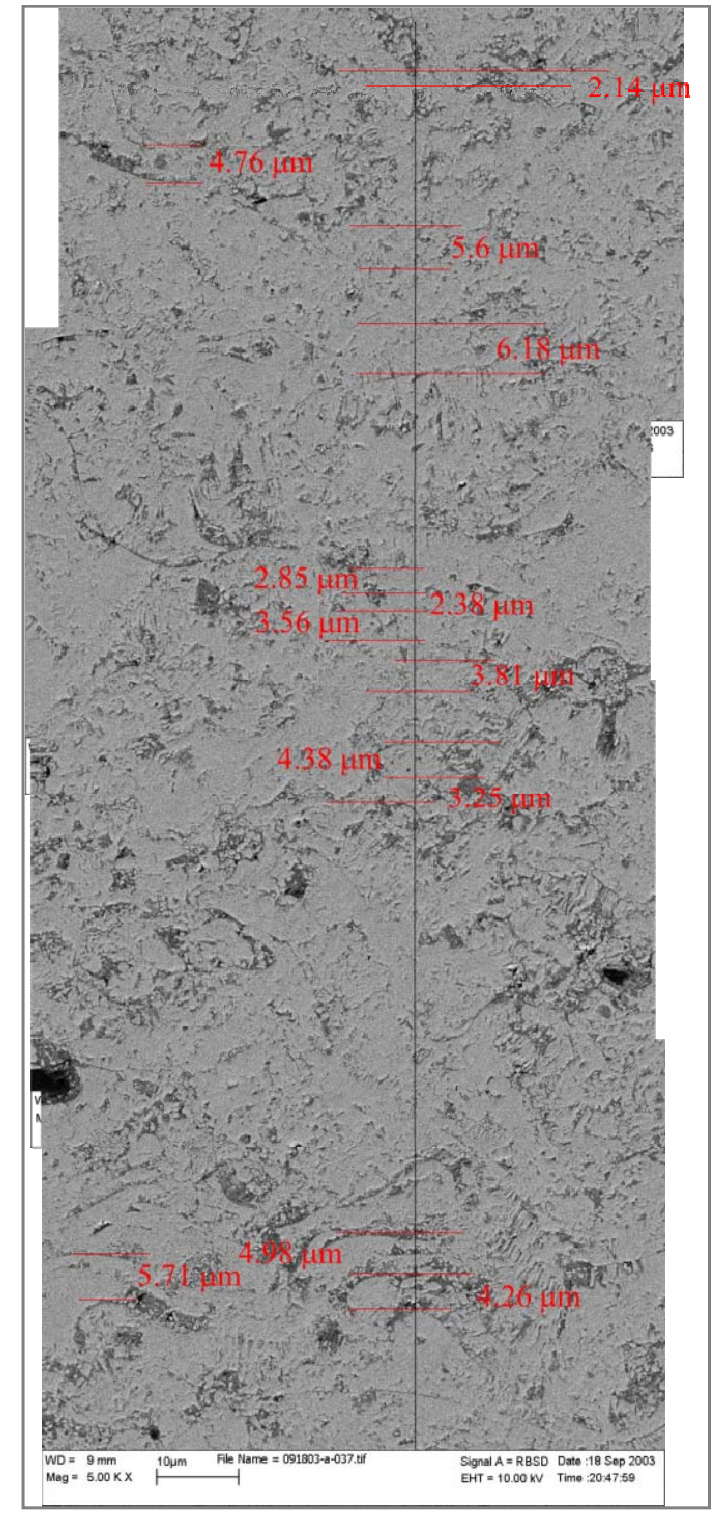

(a)
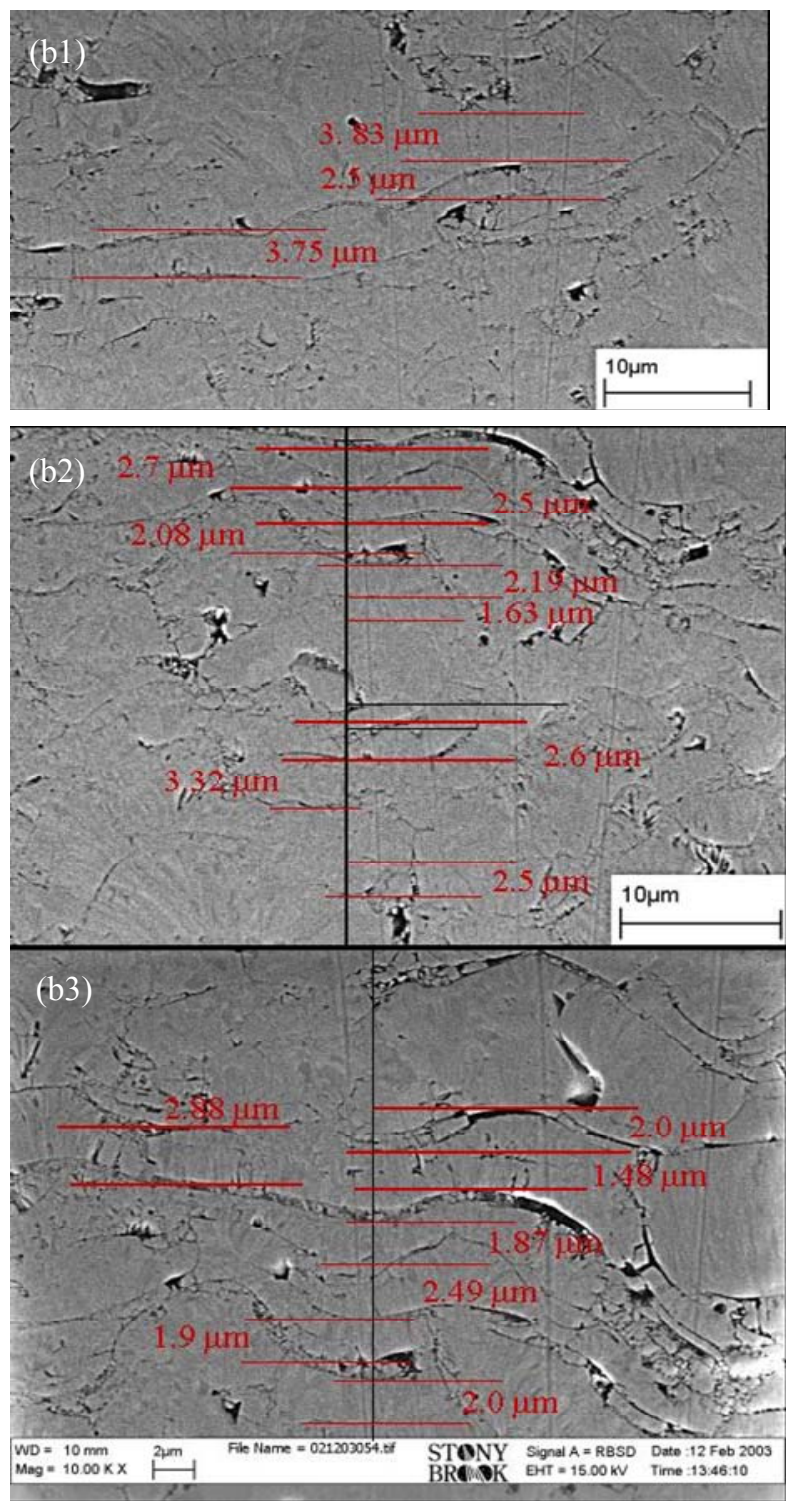

(b)

Figure 2. (a) Composite image of FC YSZ coating at 5000×; (b) Composite image of HOSP YSZ coating (b1) and (b2) at $5000 \times,(b 3)$ at $10,000 \times$.

will be 103 - 104 whereas the number of interfaces in case of a FC coating will be 61 - 62. Thus larger splat thickness translates into lower number of interfaces per given thickness of coating. This difference in the splat structure of the two coatings is not insignificant when it comes to coating properties such as thermal conductivity and elastic modulus. The implication of these results has also been discussed in more detail in another study [8].

Hence, in order to examine the influence of top coat microstructure on the TBC system's behavior under thermal exposure, different feedstock of YSZ were used to collect the splats and then these were subjected to similar heat treatments.
The two TBC system samples consisted of superalloy substrates, MCrAlY bond coats (BC) and top coats (TC) made of single splats collected using FC or HOSP YSZ powders. These were subjected to the various heat treatments as mentioned in Section 2 and are categorized as given below in Table 3 . Henceforth the samples will be referred to by the YSZ powder type and the Set number indicating the type of thermal exposure.

Specific splats were identified for each sample (powder type) and set (thermal exposure type) and the top surface microstructures as well as cross-sections of these were examined before and after thermal exposure. SEM, AFM and EDS analysis were employed for observation 
Table 3. Different types of thermal exposure treatments on FC and HOSP splats.

\begin{tabular}{cc}
$\begin{array}{c}\text { Samples } \\
\text { 1. (Substrate/BC/FC TC) }\end{array}$ & Thermal exposure \\
2. (Substrate/BC/HOSP TC) & As-sprayed splats \\
Set 1 & $\begin{array}{c}\text { Isothermally exposed in Air for } 8 \mathrm{hr} \\
\text { at } 1100^{\circ} \mathrm{C}\end{array}$ \\
Set 3 & $\begin{array}{c}\text { Isothermally exposed in Air for } 24 \mathrm{hr} \\
\text { at } 1100^{\circ} \mathrm{C}\end{array}$ \\
Set 4 & $\begin{array}{c}\text { Isothermally exposed in Vacuum for } \\
2 \text { hr at } 1100^{\circ} \mathrm{C} \text { and then Isothermally } \\
\text { exposed in Air for } 24 \text { hr at } 1100^{\circ} \mathrm{C}\end{array}$ \\
\hline
\end{tabular}

and comparison of several effects of thermal exposure.

\subsubsection{Splat Dimensions}

The top surface microstructures of the single splats of FC and HOSP YSZ taken at the same magnification before and after different exposure times in air show that the splat dimensions have not changed as an effect of thermal exposure. The cross-section images of splats are compared to show that the splat thicknesses also remain the same after thermal exposure; $2.6 \mu \mathrm{m}$ for FC and 1.49 $\mu \mathrm{m}$ for HOSP splats after $24 \mathrm{hr}$ HT and $8 \mathrm{hr}$ HT respecttively (Figure 3).

\subsubsection{Microcrack Sintering}

The microcrack network is observed in the top surface SEM micrographs of individual splats. It is seen that this network is not altered after thermal exposure at $1100^{\circ} \mathrm{C}$. Most of the fine microcracks are retained when the splats are thermally exposed in air. This is also confirmed by measuring microcrack widths in the cross-section images of splats before and after different thermal exposure times (Figure 4).

However in case of samples of Set 4 that have undergone the intermediate vacuum thermal exposure, the microcrack network is modified. Most fine microcracks in this case have started to sinter and are not as noticeable in the top surface microstructures of splats. The crosssection images also show that microcracks widths have reduced significantly after the subsequent $24 \mathrm{hr}$ Air HT (Figure 5). This indicates that the intermediate vacuum HT is responsible for instigating the sintering of these microcracks. This may be related to the increase in lattice spacing that was observed by Thornton et al. [9] when a TBC coating was heat treated in vacuum. In vacuum, there is no oxygen to replace that lost from zirconia in the formation of bond coat oxide and less oxygen appears to cause larger lattice spacing [9]. Increased lattice spacing in turn could be initiating the sintering of microcracks.

\subsubsection{TGO Growth}

Bond coat oxidation at high temperature, leads to the formation of TGO and thereby creates another layer at the interface between BC and TC. The TGO layer thickness gradually increases with HT duration.

Figure 6 shows the development and growth of the TGO layer between the bond coat and the top coat upon thermal exposure in Air at $1100^{\circ} \mathrm{C}$. It is seen that for both the powders, the samples show increased TGO thickness with increasing duration of thermal exposure. For FC YSZ samples, the TGO thickness increases from approximately $1.5 \mu \mathrm{m}$ after $8 \mathrm{hr}$ HT to $2.7 \mu \mathrm{m}$ after $24 \mathrm{hr}$ HT. For the HOSP YSZ samples, the TGO thickness is seen to increase from approximately $1.3 \mu \mathrm{m}$ after $8 \mathrm{hr}$ HT to $2.0 \mu \mathrm{m}$ after $24 \mathrm{hr}$ HT. This TGO layer is mainly constituted by Alumina since $\mathrm{Al}$ in the bond coat is preferably oxidized but at some places Chromia is also formed as disclosed by EDS. Previous studies also show that other oxides occur in isolated domains within the TBC next to the TGO and have a lighter gray contrast. These are typically spinels comprising oxides of $\mathrm{Cr} / \mathrm{Ni} / \mathrm{Co}$ often with associated internal porosity [10].

\subsubsection{Splat Surface Roughening}

Figure 7 shows the splats and large magnification images (taken at 50,000x) of their top surfaces before and after different thermal exposures. The grain structure on the splat surfaces is thereby visible. In case of both FC and HOSP splats it is observed that at the areas marked by purple arrows, the columnar grains seem to have risen upwards. A comparison of the splat surfaces between assprayed and thermally exposed splats indicates that the splat surface has roughened overall. This splat surface roughness was quantified using AFM in case of HOSP powder samples for as-sprayed splats and those exposed for $8 \mathrm{hr}$ in Air at $1100^{\circ} \mathrm{C}$. The results of this measurement are shown in Figure 8 below. The mean surface roughness of the as-sprayed splat was approximately $\mathrm{Ra}=11.9$ $\mathrm{nm}$ and that of the thermally exposed splat was approximately $\mathrm{Ra}=153 \mathrm{~nm}$.

In order to examine the cause behind the increased surface roughness, cross-sections of the splat were observed and the TGO layer generated after $24 \mathrm{hr}$ HT in Air at $1100^{\circ} \mathrm{C}$ was characterized. In most areas the TGO consists primarily of Alumina, as in Figure 9(a), but in some areas oxides like Chromia also form and exhibit a lighter grey contrast as discussed in Section 3.1.4 above. Studies have shown that such other oxides like spinels when formed also act as preferential sites for failure [10]. Reason might be that the interfacial fracture resistances of the TBC/ $\alpha$-chromia and the TBC/spinel interfaces are lower than that of the TBC/ $\alpha$-alumina interface originally present [11]. Figure 9(b) indicates the splat being lifted 


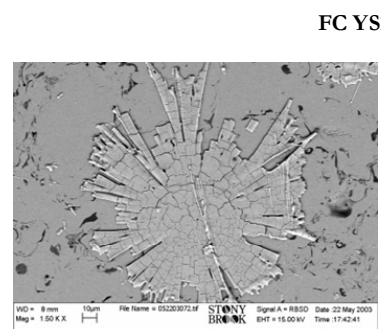

Set 1

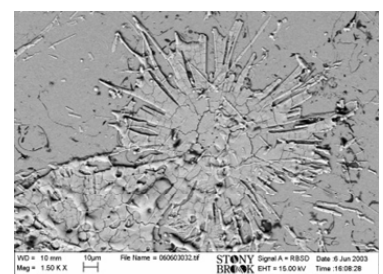

Set 1

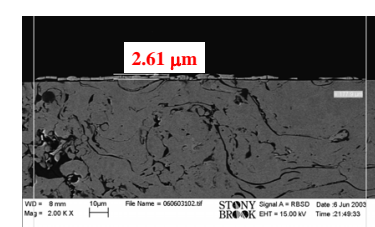

Set 1 (splat thickness)

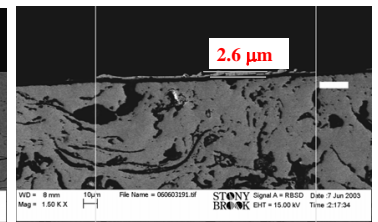

Set 3 (splat thickness)

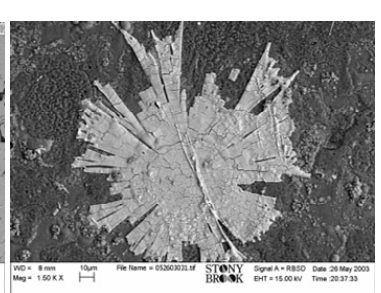

Set 2

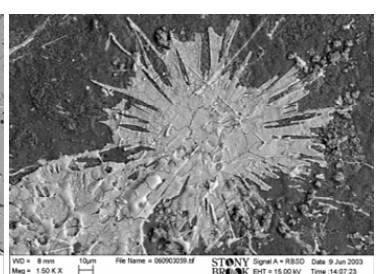

Set 3

Figure 3. Splat dimensions before and after HT in Air@1100 $\mathrm{C}$ (for FC and HOSP splats).
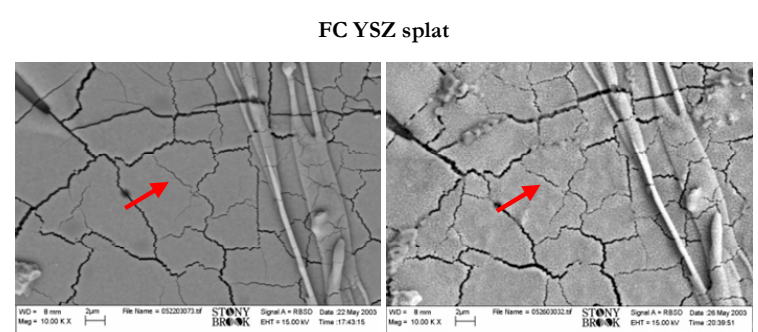

Set 1 (microcrack network)

Set 2 (microcrack network)

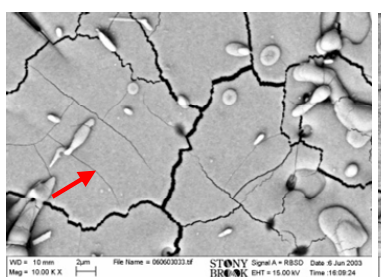

Set 1 (microcrack network)

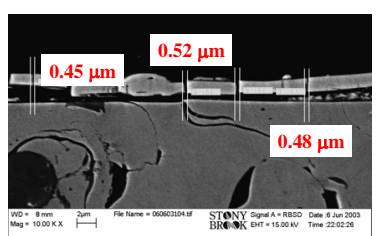

Set 1 (microcrack width)

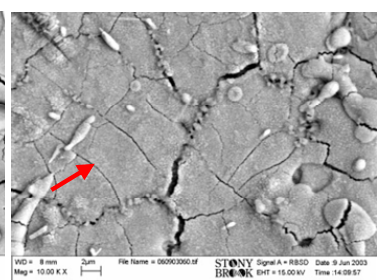

Set 3(microcrack network)

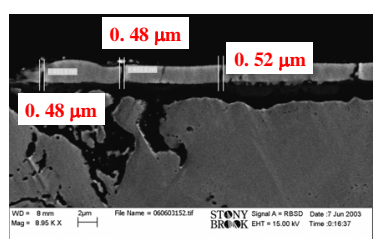

Set 2 (microcrack width)

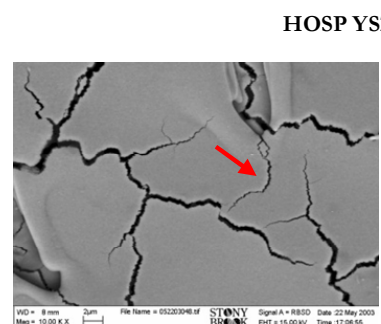

Set 1 (microcrack network)

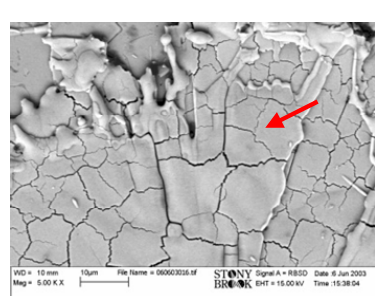

Set 1 (microcrack network)

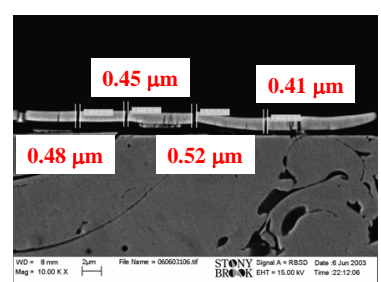

Set 1 (microcrack width)

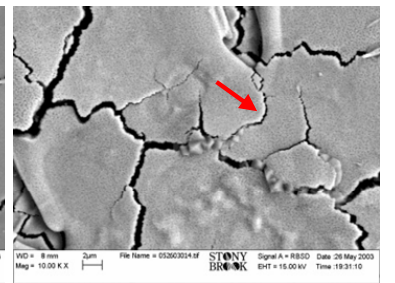

Set 2 (microcrack network)

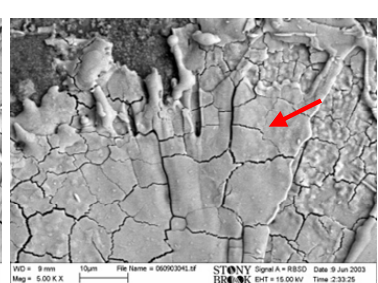

Set 3(microcrack network)

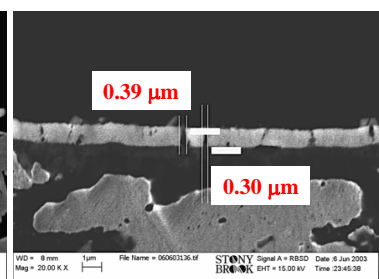

Set 2 (microcrack width)

Figure 4. Microcracks in splats before and after HT in Air@1100 $\mathrm{C}$ (for FC and HOSP splats). 


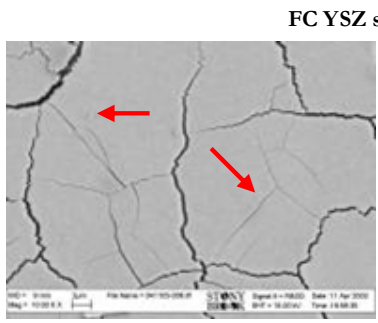

Set 1 (microcrack network)

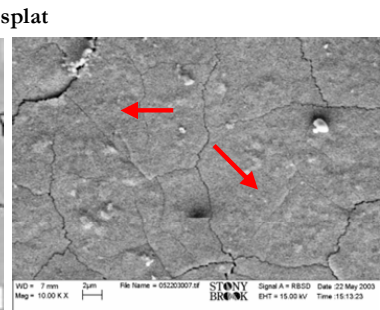

Set 4(microcrack network)

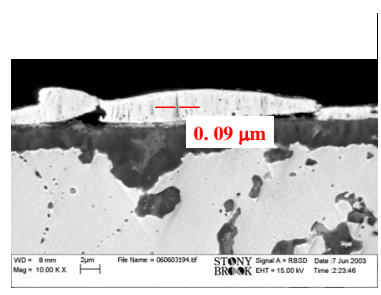

Set 4 (microcrack width)

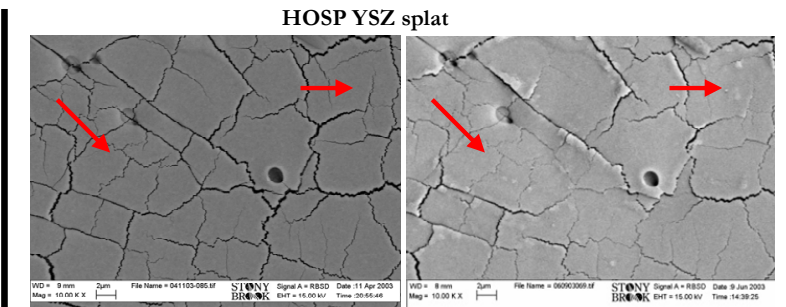

Set 4(microcrack network)

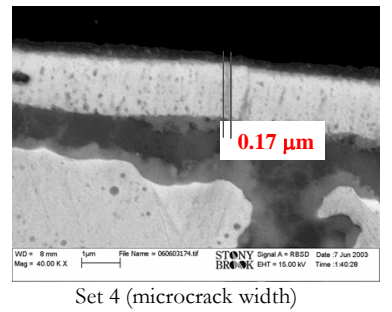

Set 1 (microcrack network)

Figure 5. Microcracks in splats before and after HT in vacuum + HT in Air@1100 ${ }^{\circ}$ (for FC and HOSP splats).

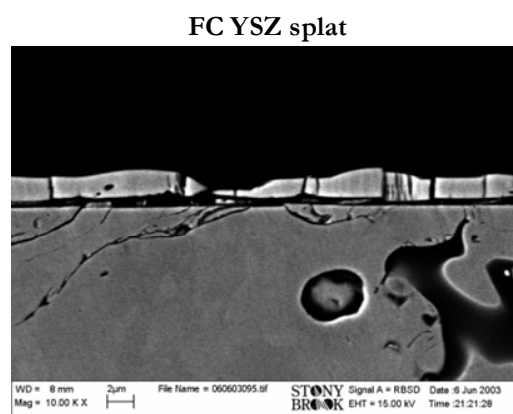

Set 1 (interface between BC and TC)

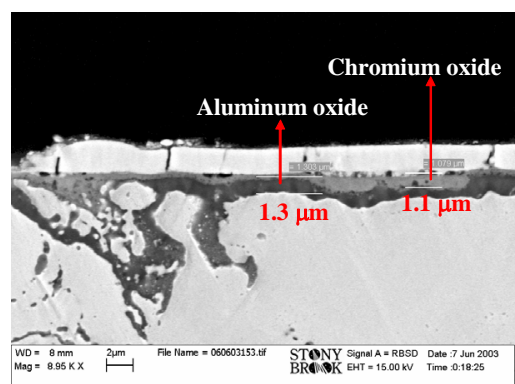

Set 2 (TGO layer between BC and TC)

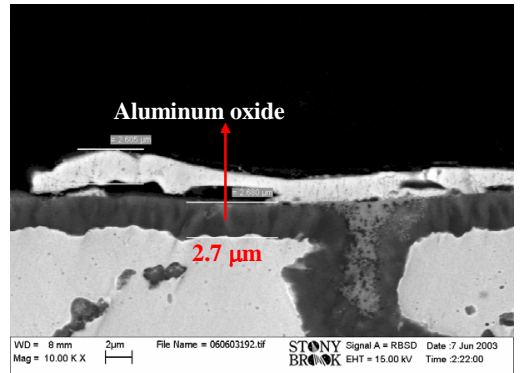

Set 3 (TGO layer between BC and TC) HOSP YSZ splat

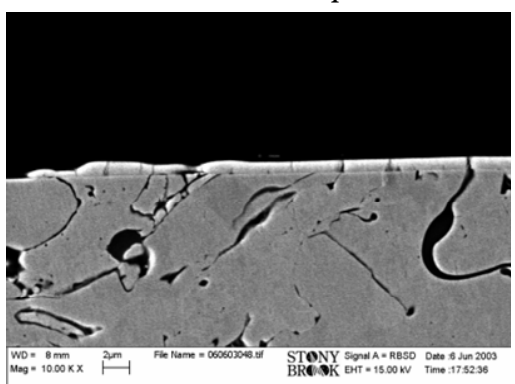

Set 1 (interface between BC and TC)

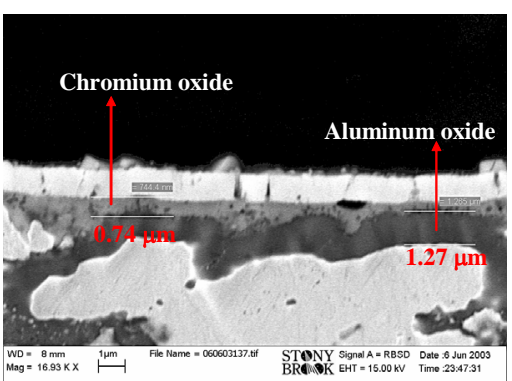

Set 2 (TGO layer between BC and TC)

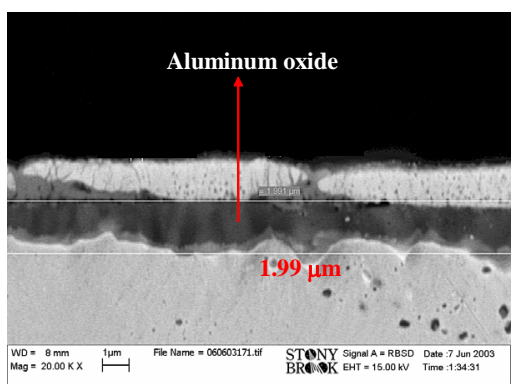

Set 3 (TGO layer between BC and TC)

Figure 6. TGO layer thickening with increasing duration of HT in Air@1100 $\mathrm{C}$ (for FC and HOSP splats). 

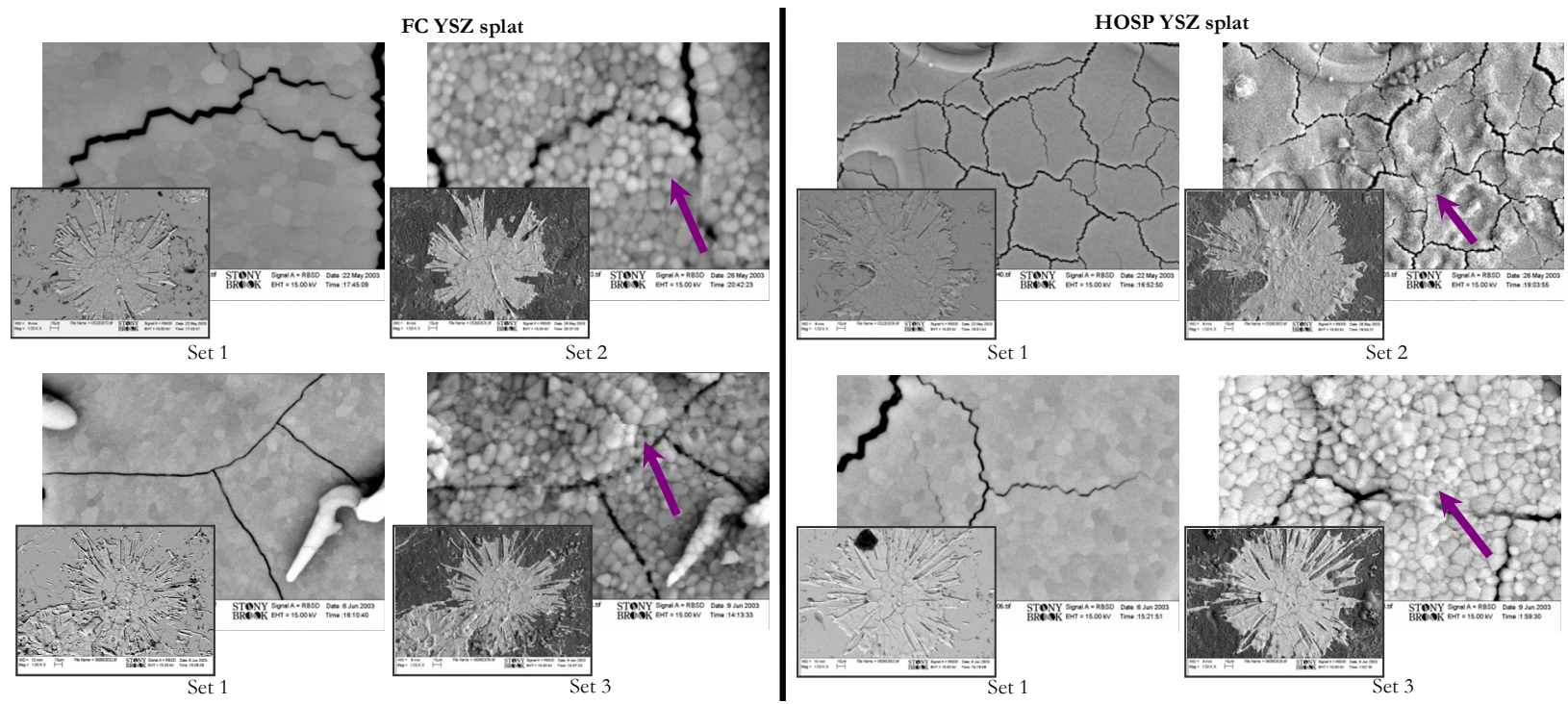

Figure 7. Roughening of splat surface due to TGO layer thickening with thermal exposure (for FC and HOSP splats).
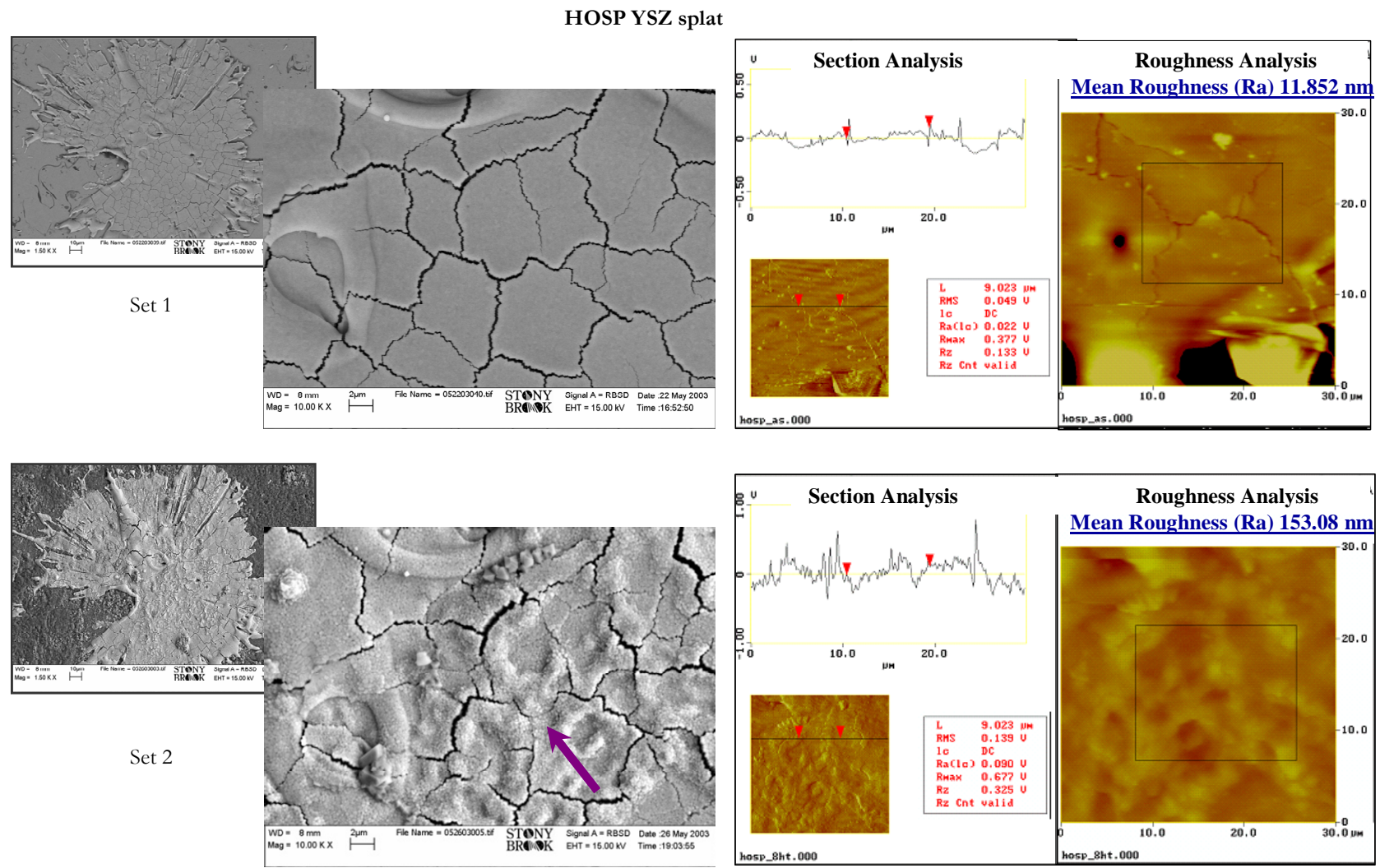

Figure 8. Roughening of splat surface due to TGO layer thickening with thermal exposure.

upwards at such a location.

Thickness imperfections in TGO enlarge in regions where $\mathrm{O}_{2}$-diffusivity through $\mathrm{TGO}$ is exceptionally large i.e. at locations where TGO contains oxides other than alumina [1]. These TGO undulations must then push the grains in the splats upward and cause splat lifting or may be spalling. This is visible in Figures 9(c) and (d) and explains the increase in surface roughness of splats as measured in Figure 8.

\subsubsection{NiO Outgrowth}

Another effect of thermal exposure is the appearance of 


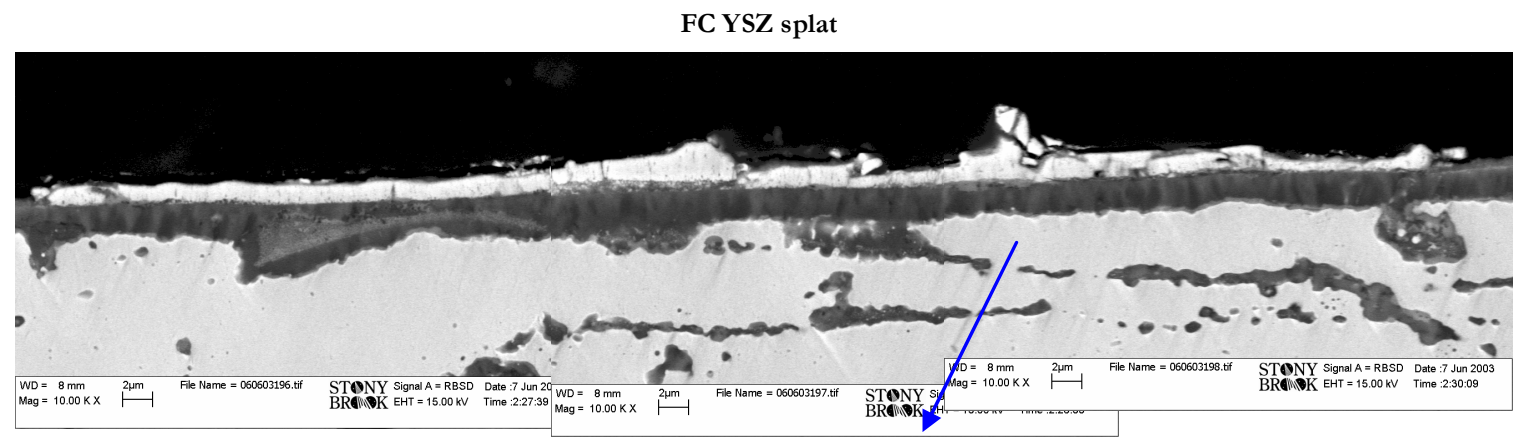

(a) Uniform TGO layer (Alumina)

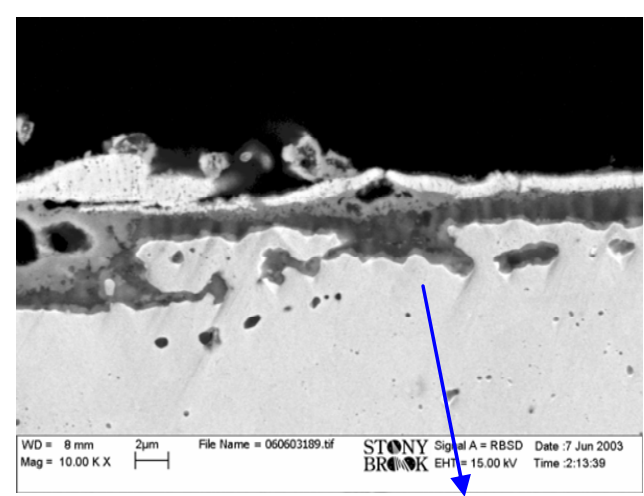

(b) Non-Uniform TGO layer (Alumina + Chromia) $\rightarrow$ splat being lifted upwards HOSP YSZ splat

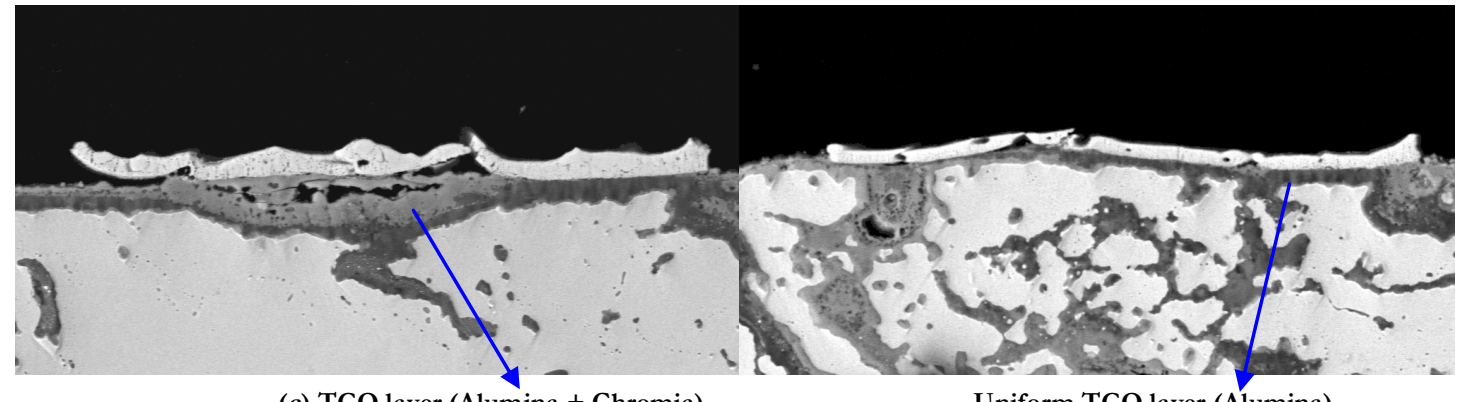

(c) TGO layer (Alumina + Chromia)

Uniform TGO layer (Alumina)

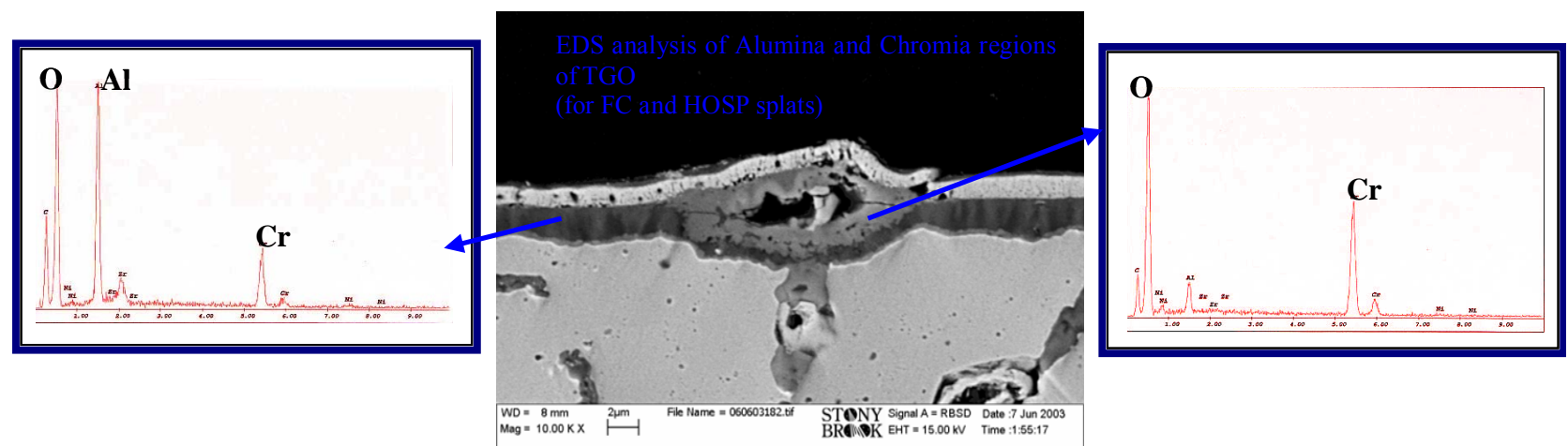

(d) Thickness imperfection in TGO layer at the location of chromia formation

Figure 9. TGO layer between bond coat and YSZ top coat $\rightarrow$ generated after $24 \mathrm{hr} \mathrm{HT}$ in Air at $1100^{\circ} \mathrm{C}$ Effect of $\mathrm{Chromia}$ formation at TGO/YSZ splat interface. 
some outward oxide growth from the bond coat, visible at larger microcracks on the top coat surface, as marked by green arrows in Figure 10. This outgrowth was assumed to originate from the bond coat oxide below the splat. It was also observed when cross-section images were examined. EDS analysis was conducted and these outgrowing oxide grains gave an EDS pattern showing $\mathrm{Ni}$ and $\mathrm{O}$ peaks, also shown in Figure 10.

APS NiCrAlY bond coat microstructure (Figure 11) contains internal oxide chunks of alumina. These regions may be locally depleted of free aluminum. Microcracks in splats are seen to coincide with oxide points in the bond-coat, Figure 11.

Several studies have shown that oxygen diffusion through TGO along grain boundaries causes more TGO growth at these boundaries $[1,12,13]$. Similarly at these microcrack positions, there is a path for oxygen to reach a $\mathrm{BC}$ area that is locally depleted of aluminum [7]. As such, other oxides could form at these microcrack positions.

However a similar investigation of the Set 4 samples that underwent the intermediate vacuum HT (Figure 12) revealed no such oxide outgrowth. The surfaces of splats indicated almost sintered microcracks and no outgrowth in the top surface as well as the cross-section images. The outward oxide growth is curtailed probably because the intermediate vacuum treatment started the sintering or sealing of most microcracks from their bottom end. One possible explanation for this microcrack sintering under vacuum has been discussed above in Section 3.1.3.

The oxide outgrowth in case of thermal exposure in Air is also thought to be related to the bond coat microstructure and will be addressed in the following Section 3.2.1.

\subsection{Effect of Variation in MCrAlY Bond Coat Microstructure}

The bond coat microstructure is greatly influenced by the spraying technique adopted for the coating formation. $\mathrm{Ni}-5 \mathrm{wt} \% \mathrm{Al}$ bond coatings obtained using four different spraying techniques are compared in Figure 13. Wire arc spraying, Air plasma spraying, HVOF spraying and Cold spraying, each differ w.r.t their feedstock injection, melting methods, spraying parameters as well as oxidation involved during spraying. As such they result in distinct particle conditions during flight. Wire arc and APS generate lower particle velocities compared to HVOF and Cold spray. HVOF sprayed droplets have lower temperatures and Cold spray is a unique process in which entire deposition takes place in the solid state [14].

As such these processes lead to distinct differences in the microstructures of coatings produced. The porosity and oxide content in the micrographs are estimated using
Image analysis, shown in Figure 14.

Both wire arc and APS coatings show significant oxidation and porosity. HVOF coating depicts a much lower "dark area" but a significant portion of this is oxide. Cold-spray coatings indicate low porosity and almost no oxide formation, probably due to high impact velocities and low process temperatures.

Figure 15 summarizes the process of bond coat microstructure evolution by describing the key mechanisms involved during spraying such as in-flight oxidation, single splat formation, post-impact oxidation and splat-splat linkage leading to coating buildup. Schematics for mechanisms and corresponding microstructural observations are shown.

Oxide segregation during in-flight oxidation in case of APS process causes splashing of oxide beneath the splat, whereas in case of HVOF spraying, complete spreading of splat before solidification generates very flat, disk shaped splats having better contact with substrate. Less inflight oxidation and slow solidification in the HVOF process generates an $\mathrm{Al}$ depletion region below the post impact oxidation on splat surface. Post impact oxidation in case of APS splats however, generates poorer wetting and gives rise to lamellar porosity between the new splat and oxide of the previous layer. Metal-metal contact in both processes generates inter-splat coalescence.

Nano scale observations revealed oxide bands after every splat in case of APS coating and more splat coalescence in HVOF coating. Phases in each coating were analyzed showing fcc $\mathrm{Ni}$ as the primary phase in APS and gamma-Ni (richer in $\mathrm{Al}$ ) in case of HVOF. The above observations are investigated and discussed in detail elsewhere [7].

These observations make it very apparent that the choice of bond coat will also play a role in the high temperature behavior of the TBC system as the bond coat is an integral component of such a system. Hence, in order to examine the influence of bond coat microstructure on the TBC system's behavior under thermal exposure, bond coats sprayed by different techniques were used. Top coat splats were collected on these bond coat surfaces and the obtained TBC systems as a whole were then subjected to similar heat treatments. Table 4 shows a list of the samples used.

The top surfaces of splats and cross-sections of coatgs were compared before and after thermal exposure. Once again different effects of thermal exposure were observed upon examination.

\subsubsection{NiO Outgrowth-HT in Air}

Figure 16 shows the as-sprayed splats and the splats after $8 \mathrm{hr} \mathrm{HT}$ in Air at $1100^{\circ} \mathrm{C}$ on APS, HVOF and VPS bond coat surfaces. 

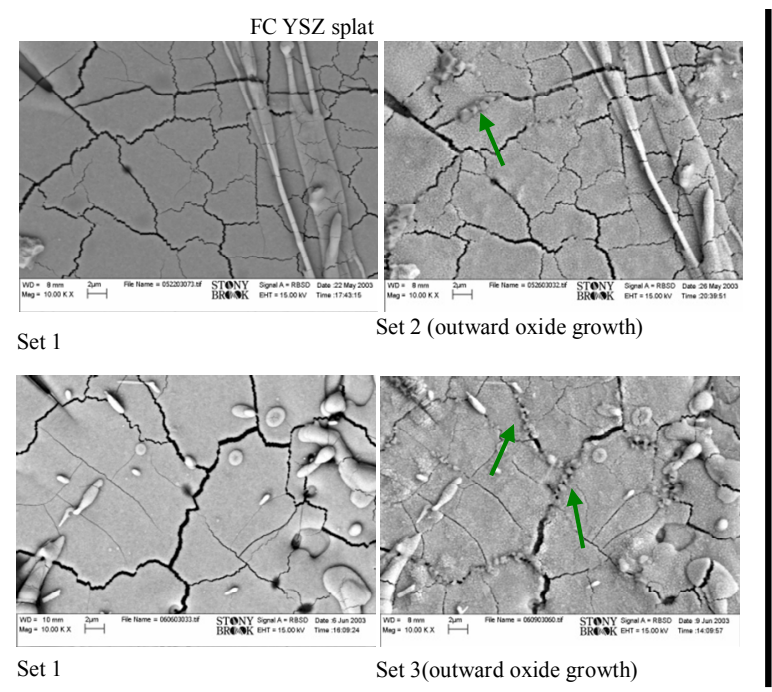

Set 1

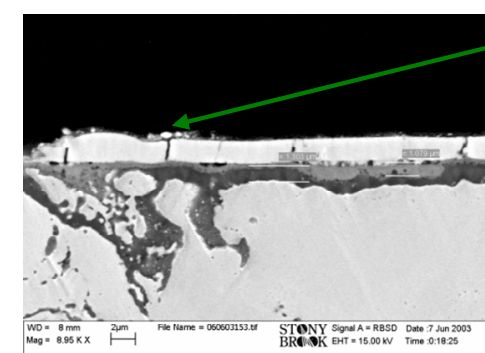

FC Set 2 (outward oxide growth)

EDS analysis of Oxide outgrowth

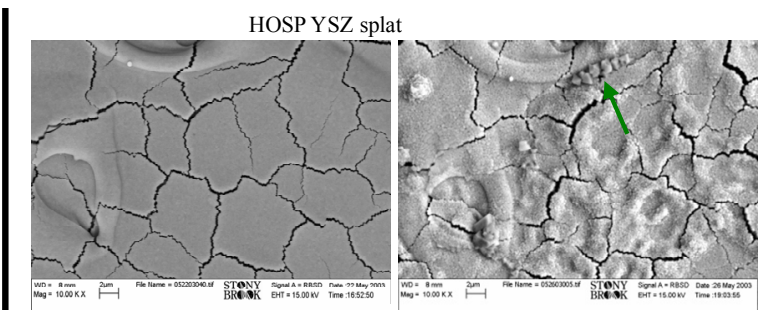

Set 2 (outward oxide growth)

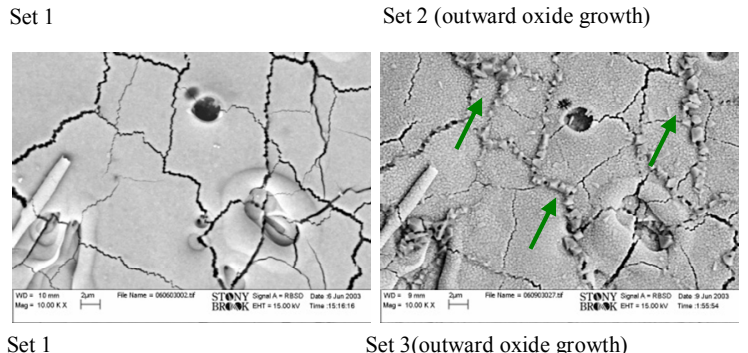

Set 3(outward oxide growth)
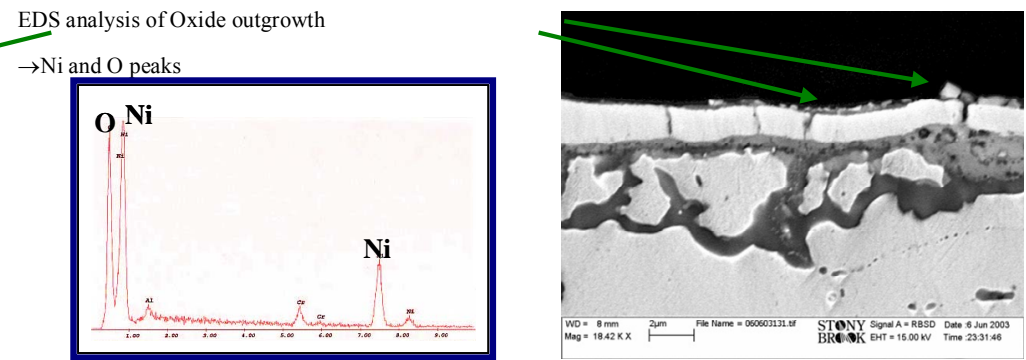

HOSP Set 2 (outward oxide growth)

Figure 10. NiO outgrowth through microcracks in splats after HT in Air @ $1100^{\circ} \mathrm{C}$ (for FC and HOSPsplats).

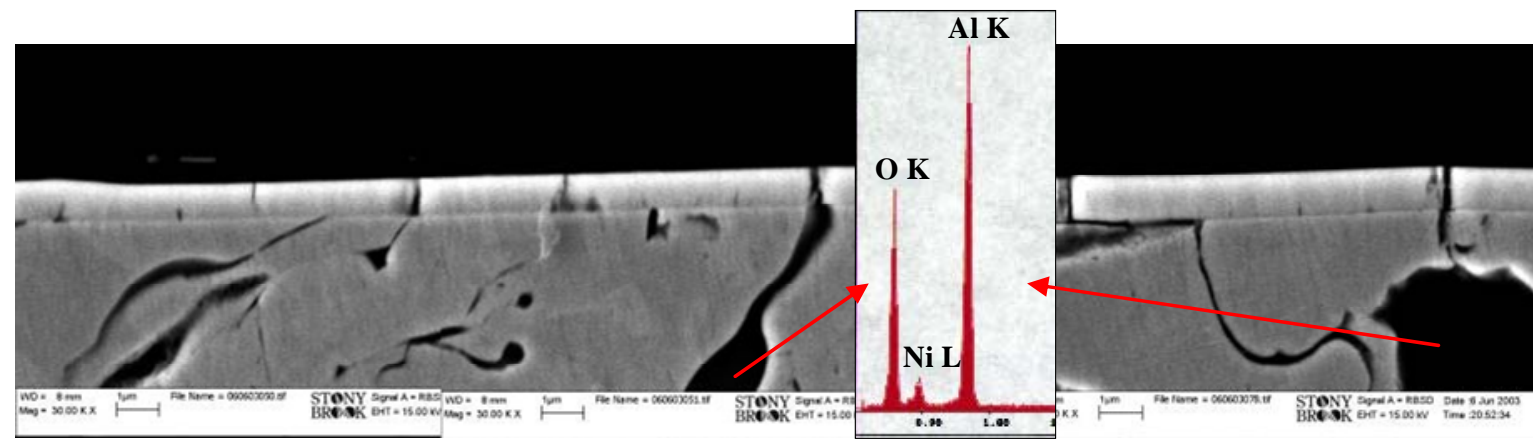

Figure 11. Microcracks coinciding with oxide points.

Table 4. Different types of thermal exposure treatments on FC and HOSP splats.

\begin{tabular}{ccc}
\hline No. & TBC system components & Thermal exposure \\
\hline $\begin{array}{c}\text { Single splats of YSZ on } \\
\text { coat }\end{array}$ & $\begin{array}{c}\text { Isothermally exposed in Air } \\
\text { for } 8 \mathrm{hr} \text { at } 1100^{\circ} \mathrm{C}\end{array}$ \\
$\begin{array}{c}\text { Thin YSZ coating on APS } \\
\text { bond coat }\end{array}$ & $\begin{array}{c}\text { Isothermally exposed in Air } \\
\text { for } 24 \mathrm{hr} \text { at } 1100^{\circ} \mathrm{C}\end{array}$ \\
& $\begin{array}{c}\text { Isothermally exposed in Vacuum for } \\
2 \mathrm{hr} \text { at } 1100^{\circ} \mathrm{C} \& \text { then Isothermally } \\
\text { exposed in Air for } 24 \mathrm{hr} \text { at } 1100^{\circ} \mathrm{C}\end{array}$ \\
3. Thin YSZ coating on HVOF \\
bond coat
\end{tabular}

In case of APS bond coat, outward oxide growth and splat surface roughening is observed as discussed before in Sections 3.1.6 and 3.1.5 respectively. But in case of HVOF and VPS bond coats, no such oxide outgrowth is seen and splat surface roughening is also minimal.

The HVOF and VPS bond coats have much lesser inherent oxidation as seen in Section 3.2. Lesser in-flight oxidation was reported for HVOF compared to APS and of course VPS process pretty much eliminates oxidation during spraying. As such, the $\mathrm{Al}$ concentration in the $\mathrm{BC}$ is uniform, there are no alumina chunks, and microcracks cannot coincide with any Al depleted areas. This natu- 


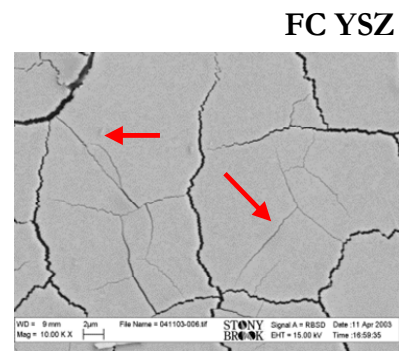

Set 1

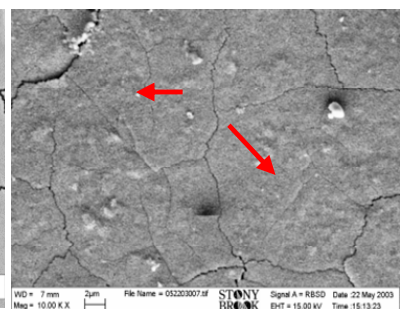

Set 4 (no oxide outgrowth)
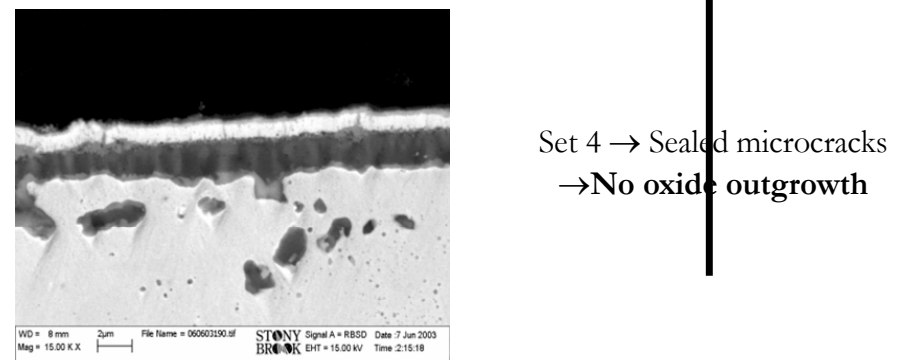

HOSP YSZ splat

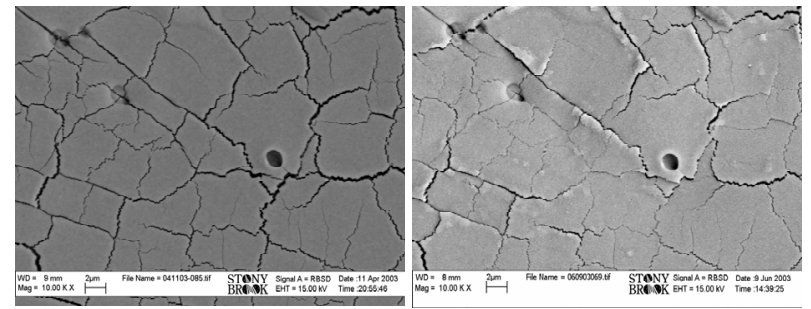

Set 1
Set 4 (no oxide outgrowth)

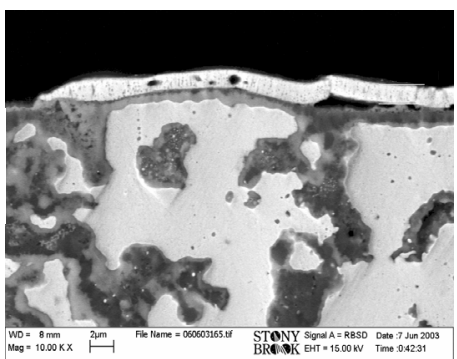

Figure 12. Microcracks in splats before and after HT in Vacuum + HT in Air@1100 ${ }^{\circ} \mathrm{C}$ (for FC and HOSP splats).

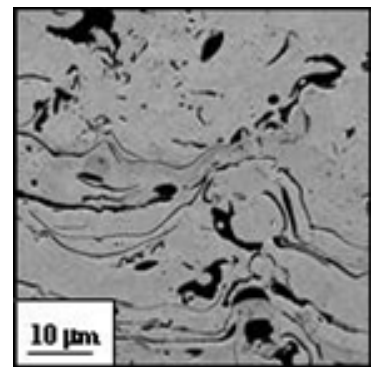

Wire Arc coating showing thicker splats

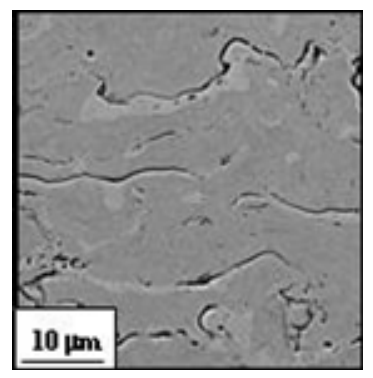

HVOF coating showing very

few visible splat boundaries

Figure 13. Bond coat microstructures using different spraying techniques.

rally precludes the abovementioned method of formation of $\mathrm{NiO}$.

\subsubsection{Sintering Under High Temperature}

Figure 17 shows TBC samples of thin YSZ coating on APS BC and thin YSZ coating on HVOF bond coat subjected to the $24 \mathrm{hr}$ HT in Air at 1100 degrees.

Careful examination shows visible sintering of inter-

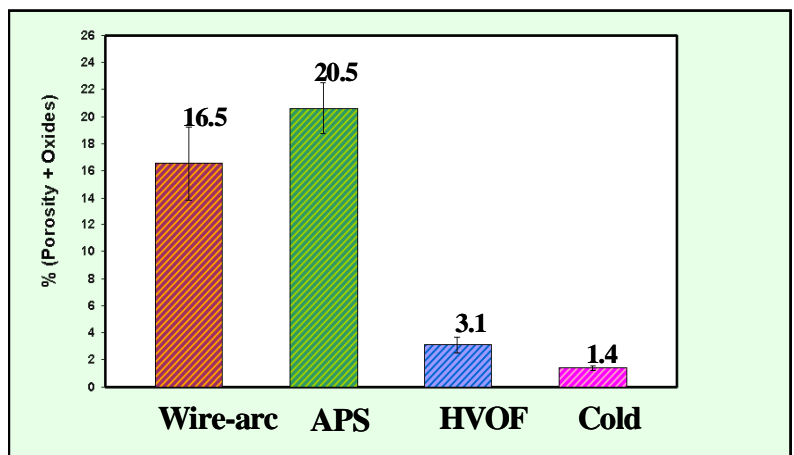

Figure 14. Porosity and oxide content in bond coat microstructures obtained using image analysis.

lamellar pores and intersplat boundaries in the APS BC sample, as marked by yellow arrows. Most microcracks are however still retained as indicated by red star symbols. Whereas, upon inspection of the HVOF BC sample, interlamellar pores and intersplat boundaries are seen to be still present as shown by pink arrows and red stars indicate that microcracks have started sintering.

Although this is not completely understood, one possible theory is that as observed before, during HT in Air, $\mathrm{NiO}$ outgrowth occurs through microcracks of YSZ splats on APS BC whereas; this is not the case with HVOF bond coats. Since this basic hindrance to sintering (blocking of microcracks) is now missing, the microcracks can sinter.

If these same samples are subjected to intermediate vacuum HT and then the $24 \mathrm{hr}$ Air HT (Figure 18), then however, most microcracks are seen to have sintered in case of both bond coat samples. This is in agreement 


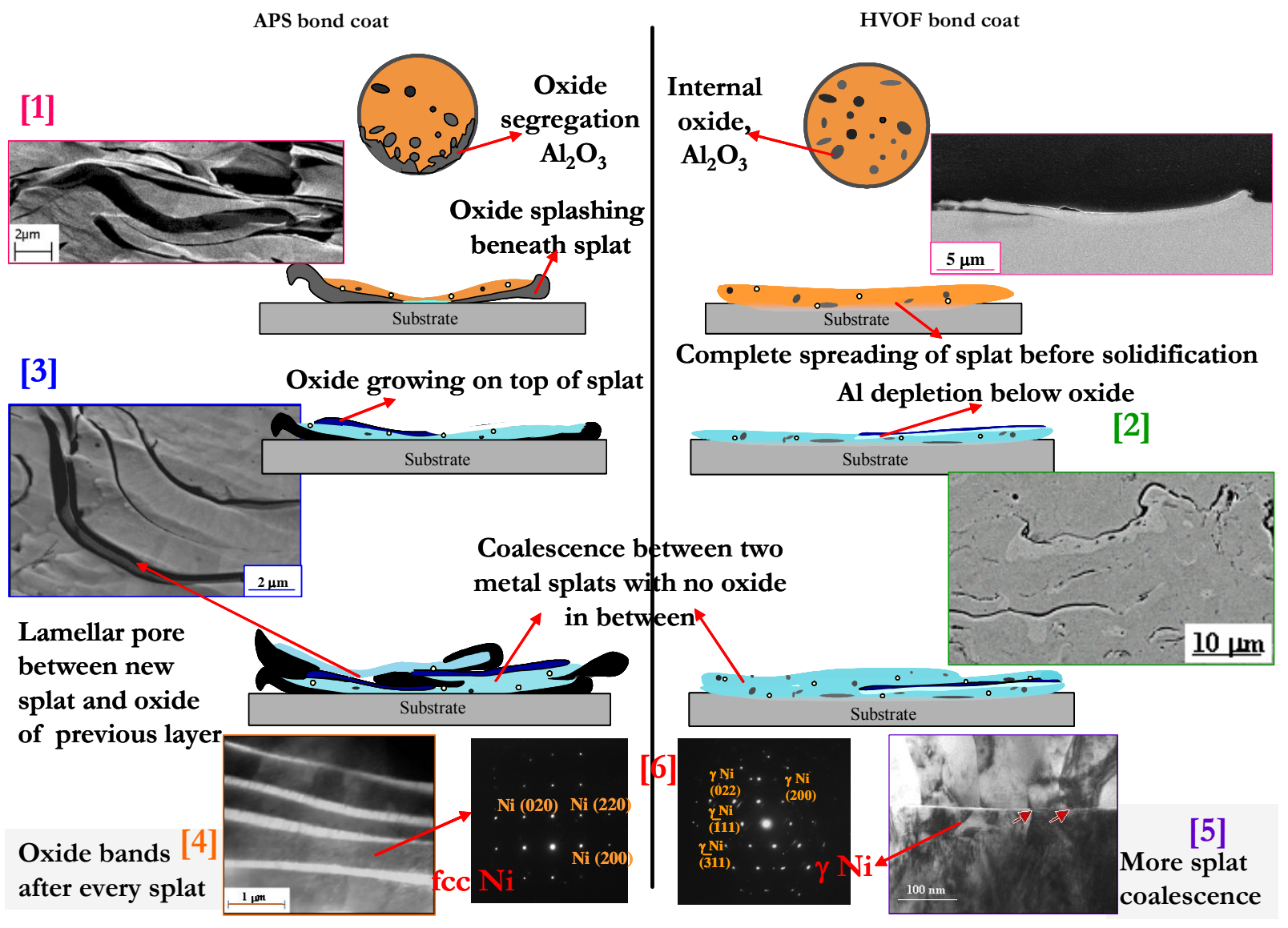

Figure 15. Bond coat microstructure evolution-influence of spray process.

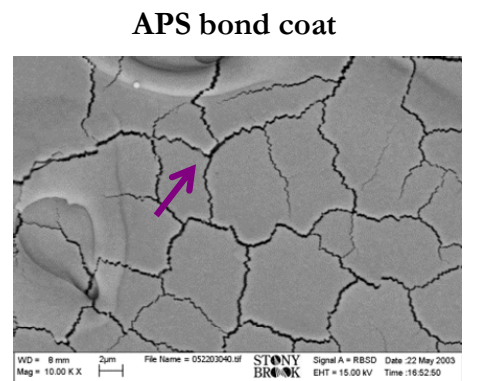

Set 1

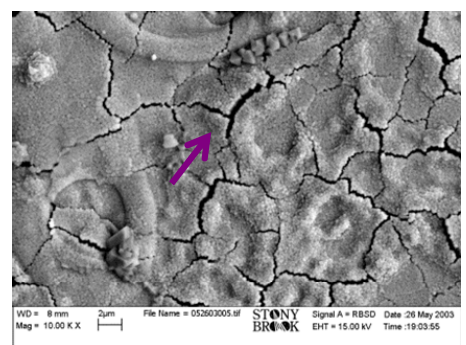

Set 2 (splat surface roughening and oxide outgrowth)

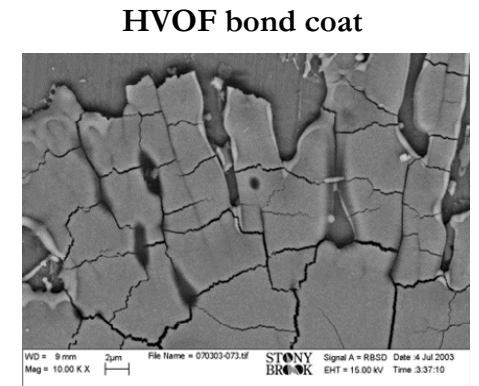

Set 1

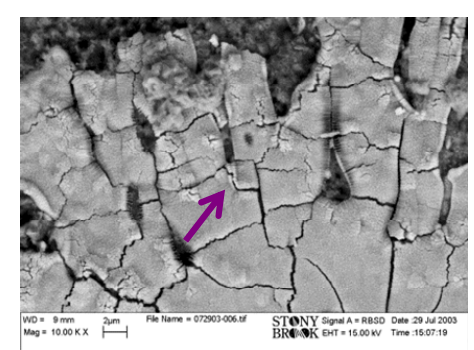

Set 2 (less splat surface roughening, no oxide outgrowth)

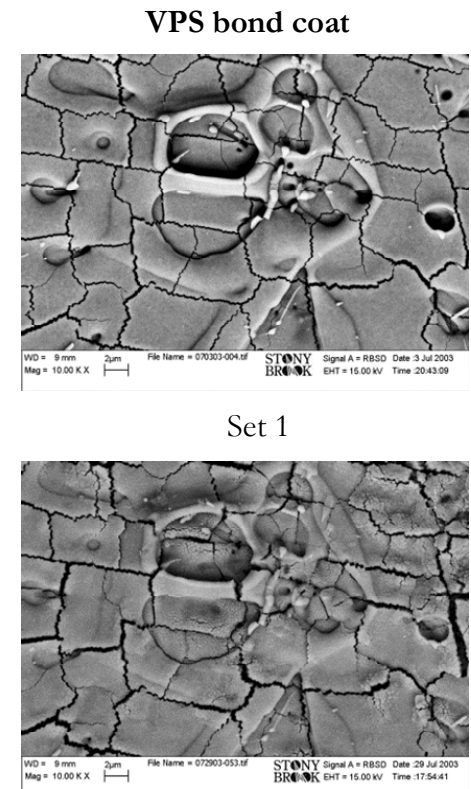

Set 2 (no splat surface roughening and no oxide outgrowth)

Figure 16. Effects on top coat single splats after 8 hr HT in Air@1100 ${ }^{\circ}$ (for APS, HVOF and VPOS bond coats). 

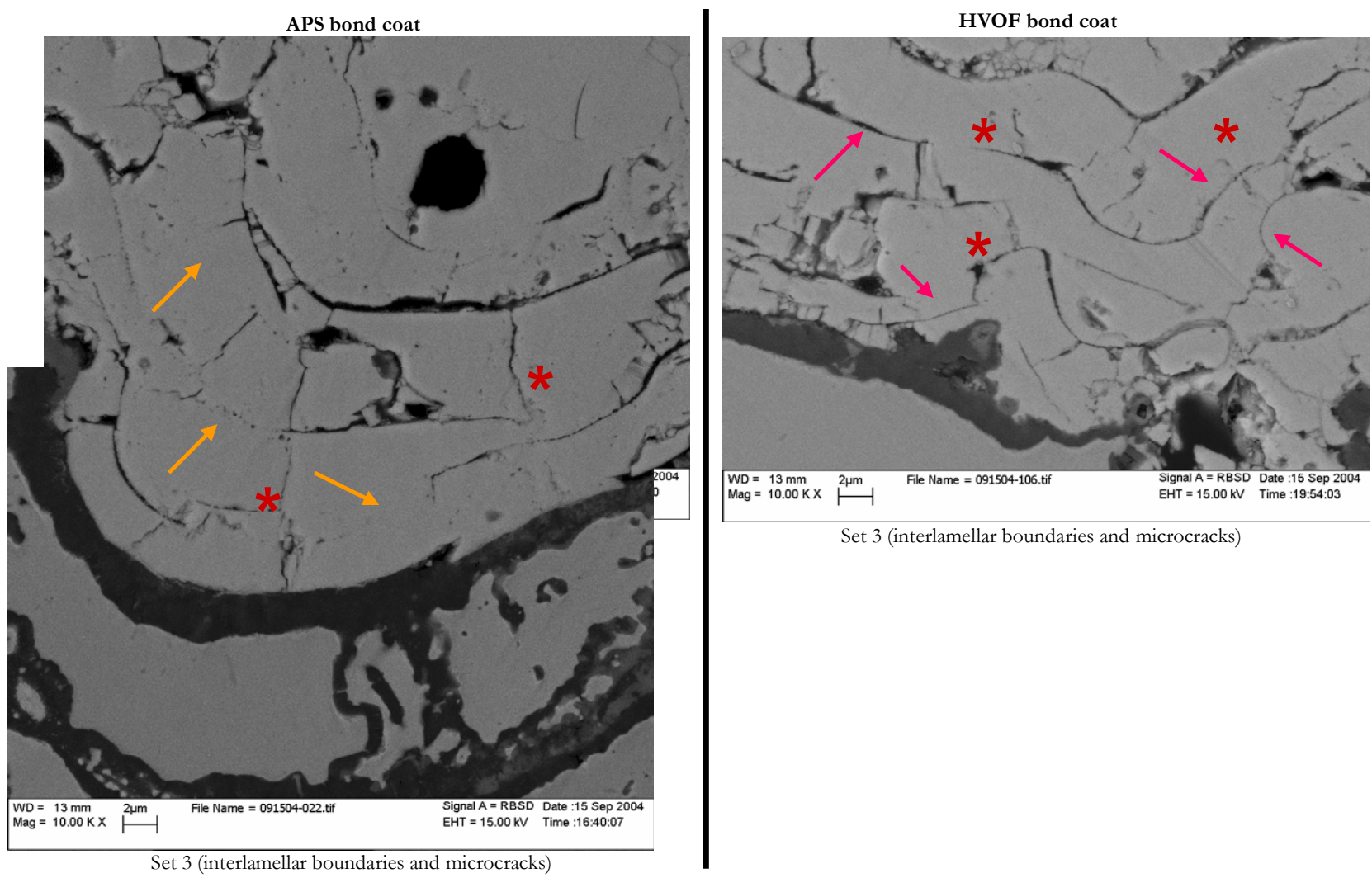

Figure 17. Sintering in top coat after 24 hr HT in Air@1100 ${ }^{\circ}$ (for APS and HVOF bond coats).
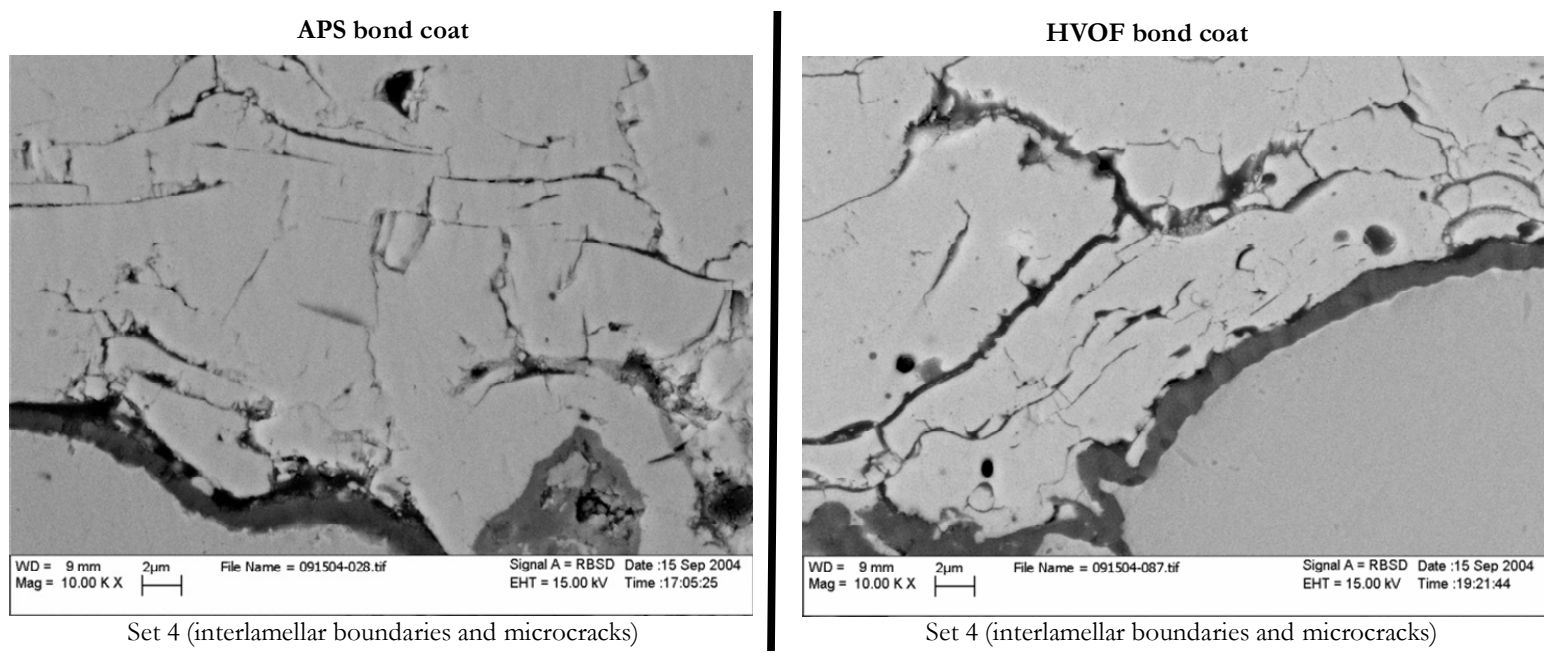

Figure 18. Sintering in top coat after 2 hr HT in Vacuum + 24 hr HT in Air@1100 ${ }^{\circ}$ (for APS and HVOF bond coats).

with the previous observations made in case of single splats.

\subsubsection{TGO Growth}

The TGO formation in these samples with different bond coats was also considered and is illustrated in Figure 19. For the same duration of HT i.e. $24 \mathrm{hr}$ in Air at 1100 degrees, APS bond coat shows faster TGO growth than
HVOF bond coat. The TGO thickness is seen to be 2.7 $\mu \mathrm{m}$ for APS bond coat sample and $1.7 \mu \mathrm{m}$ for the HVOF bond coat sample.

\subsubsection{TGO Imperfections}

When the elemental composition along the TGO in both samples is compared, then for the APS bond coat sample, many locations along the TGO length show formation of 
other oxides like Chromia.However, for the HVOF bond coat sample, although some locations show TGO thickening, chromia formation is not visible. This is clearly shown in Figure 20.

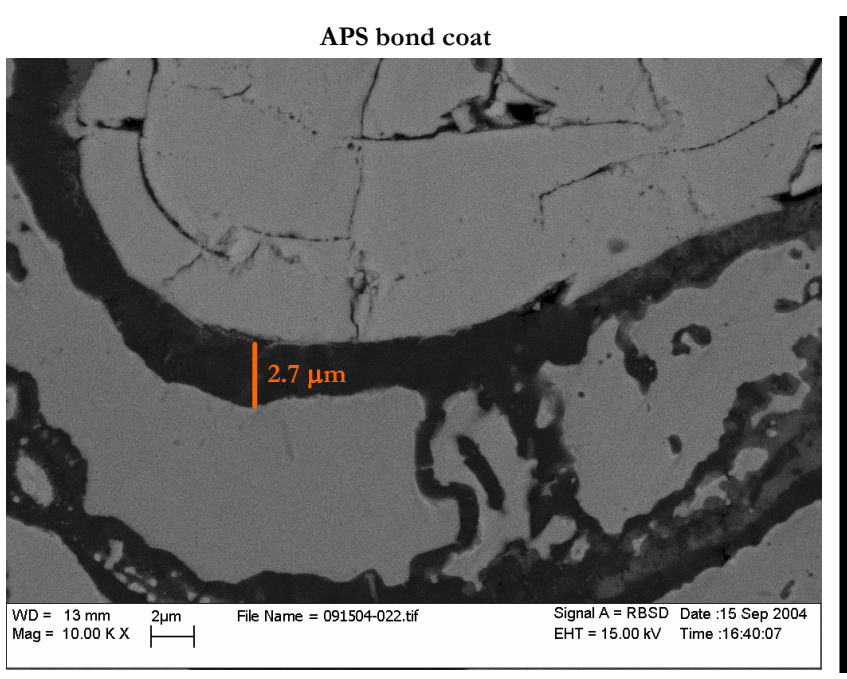

Once again this is related to inherent oxidation levels in both bond coats. APS bond coats have undergone more oxidation during their formation and hence have lesser free $\mathrm{Al}$ available for TGO formation. Al depletion

Figure 19. TGO growth after 24 hr HT in Air@1100 $\mathrm{C}$ (for APS and HVOF bond coats).

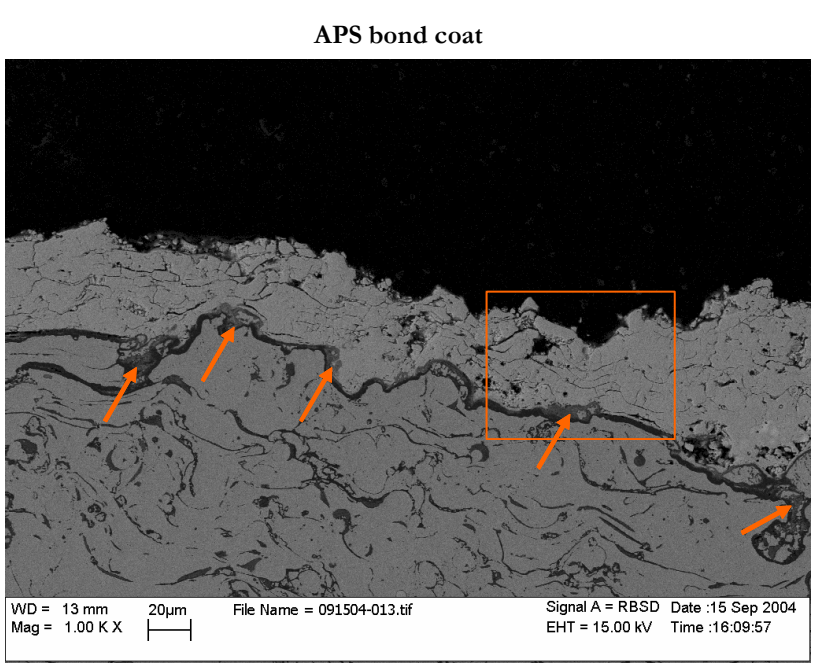

Set 4 (TGO layer at BC/TC interface)

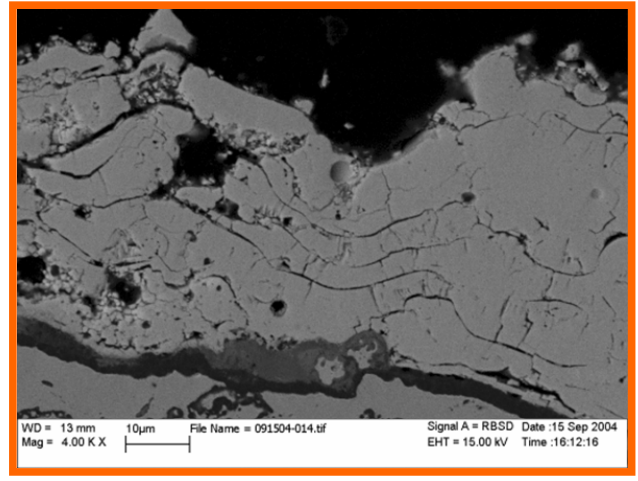

Locations of Chromia formation

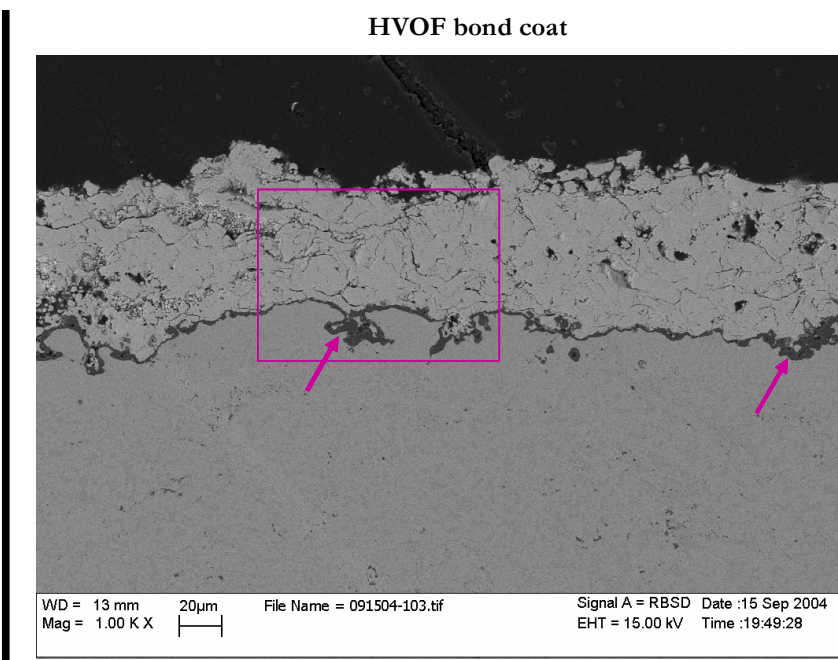

Set 4 (TGO layer at BC/TC interface)

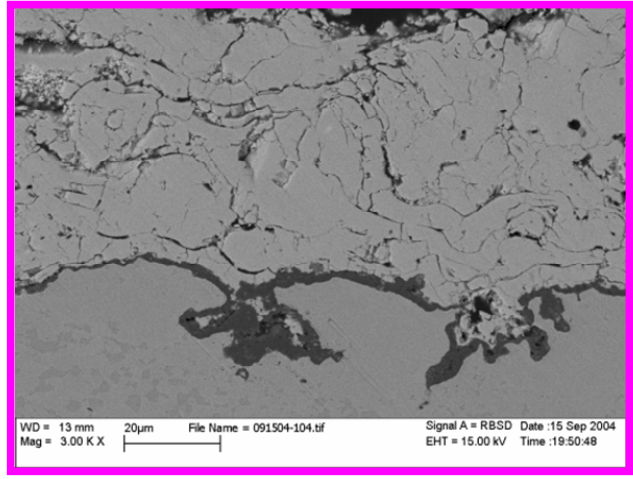

TGO thickening but no Chromia formation

Figure 20. Thickness imperfections in TGO — thickening and formation of other oxides (for APS and HVOF bond coats). 
in $\mathrm{BC}$ causes other oxides to form, as also shown by Tolpygo and Clarke $[15,16]$. HVOF bond coats have more free $\mathrm{Al}$ retained in the coating and hence they have a longer way to go before $\mathrm{Al}$ depletion occurs.

Fewer instances of chromia formation means fewer occurrences of thickness imperfections in the TGO layer and hence reduced splat surface roughening in case of HVOF and VPS bond coats. This further explains the observations in Figure 16, Section 3.2.1.

\section{Conclusions}

In this study, the following effects of thermal exposure were considered and compared as an outcome of variations in top coat splat dimensions and bond coat microstructures.

- Microcracks sintering in splats.

- TGO growth at interface between top coat and bond coat.

- Splat surface roughening.

- $\mathrm{NiO}$ outgrowth occurring through microcracks in splats.

- Effect of intermediate Vacuum HT during thermal exposure.

It was seen that in case of top coat, different YSZ feedstock give different initial splat dimensions in the as-sprayed splats but the splats show the same high temperature behavior when subjected to similar heat treatments. Intermediate vacuum heat treatment alters the microcrack sintering behavior observed for Air heat treatment and also prevents the $\mathrm{NiO}$ outgrowth upon thermal exposure. But these effects are also similar for both YSZ powders. So, the top coat microstructure with respect to single splats does not have an influence on high temperature behavior of the system.

In case of bond coats, however, when different spraying techniques are used, the inherent oxidation levels in the bond coat microstructures are different and this does influence the behavior of the system upon high temperature exposure.

The free $\mathrm{Al}$ available in the $\mathrm{BC}$ for TGO formation dictates the occurrence of chromia formation and hence determines the extent of TGO thickness imperfections leading to splat surface roughening or spallation.

Absence of Alumina chunks in the HVOF and VPS bond coat microstructures prevents the described method of formation of $\mathrm{NiO}$ outgrowth through microcracks and stimulates microcracks sintering which is not observed in APS bond coats under similar thermal exposure.

\section{Acknowledgements}

We would like to thank Glenn Bancke, AnirudhaVaidya, John Gutleber and Li Li (CTSR) for preparation of the specimens and spraying diagnostics.

\section{REFERENCES}

[1] A. G. Evans, D. R. Mumm, J. W. Hutchinson, G. H. Meier and F. S. Pettit, "Mechanisms Controlling the Durability of Thermal Barrier Coatings," Progress in Materials Science, Vol. 46, No. 5, 2001, pp. 505-553. doi:10.1016/S0079-6425(00)00020-7

[2] A. Nusair Khan and J. Lu, "Behavior of Air Plasma Sprayed Thermal Barrier Coatings, Subject to Intense Thermal Cycling," Surface and Coatings Technology, Vol. 166, No. 1, 2003, pp. 37-43. doi:10.1016/S0257-8972(02)00740-5

[3] A. Rabiei and A. G. Evans, "Failure Mechanisms Associated with the Thermally Grown Oxide in Plasma Sprayed Thermal Barrier Coatings," Acta Materialia, Vol. 48, No. 15, 2000, pp. 3963-3976. doi:10.1016/S1359-6454(00)00171-3

[4] A. Kulkarni, S. Sampath, A. Goland and H. Herman, "Porosity-Thermal Conductivity Relationships in Plasma Sprayed Zirconia Coatings," In: C. C. Berndt, Ed., Thermal Spray: Surface Engineering via Applied Research (ITSC 2000), ASM International, Materials Park, Montreal, 8-11 May 2000, pp. 1061-1066.

[5] A. Kulkarni, Z. Wang, T. Nakamura, S. Sampath, A. Goland, H. Herman, A. J. Allen, J. Ilavsky, G. Long, J. Frahm and R. W. Steinbrech,"Comprehensive Microstructural Characterization and Predictive Property Modeling of Plasma-Sprayed Zirconia Coatings," Acta Materialia, Vol. 51, No. 9, 2003, pp. 2457-2475. doi:10.1016/S1359-6454(03)00030-2

[6] S. Deshpande, A. Kulkarni, S. Sampath and H. Herman, "Application of Image Analysis for characterization of Porosity in Thermal Spray Coatings and Correlation with Small Angle Neutron Scattering," Surface and Coatings Technology, Vol. 187, No. 1, 2004, pp. 6-16.

doi:10.1016/j.surfcoat.2004.01.032

[7] S. Deshpande, S. Sampath and H. Zhang, "Mechanisms of Oxidation and Its Role in Microstructural Evolution of Metallic Thermal Spray Coatings - Case study for NiAl," Surface and Coatings Technology, Vol. 200, No. 18-19, 2006, pp. 5395-5406. doi:10.1016/j.surfcoat.2005.07.072

[8] Z. Wang, A. Kulkarni, S. Deshpande, T. Nakamura and H. Herman, "Computational Approaches to Estimate Properties of Thermally Sprayed Porous Coatings," Acta Materialia, Vol. 51, No. 18, 2003, pp. 5319-5334. doi:10.1016/S1359-6454(03)00390-2

[9] J. Thornton, D. Cookson and E. Pescott, "The Measurement of Strains within the bulk of Aged and As-Sprayed Thermal Barrier Coatings Using Synchrotron Radiation," Surface and Coatings Technology, Vol. 120-121, 1999, pp. 96-102. doi:10.1016/S0257-8972(99)00340-0

[10] A. Rabiei and A. G. Evans, "Failure Mechanisms Associated with the Thermally Grown Oxide in Plasma Sprayed Thermal Barrier Coatings," Acta Materialia, Vol. 48, No. 15, 2000, pp. 3963-3976. doi:10.1016/S1359-6454(00)00171-3 
[11] E. A. G. Shillington and D. R. Clarke, "Spalling Failure of a Thermal Barrier Coating Associated with Aluminum Depletion in the Bond-Coat," Acta Materialia, Vol. 47, No. 4, 1999, pp. 1297-1305. doi:10.1016/S1359-6454(98)00407-8

[12] T. Xu, M. Y. He and A. G. Evans, "A Numerical Assessment of the Durability of Thermal Barrier Systems That Fail by Ratcheting of the Thermally Grown Oxide," Acta Materialia, Vol. 51, No. 13, 2003, pp. 3807-3820. doi:10.1016/S1359-6454(03)00194-0

[13] A. M. Karlsson, J. W. Hutchinson and A. G. Evans, "The Displacement of the Thermally Grown Oxide in Thermal Barrier Systems upon Thermal Cycling," Materials Science and Engineering, Vol. 35, No. 1-2, 2003, pp. 244257. doi:10.1016/S0921-5093(02)00843-2
[14] S. Deshpande, S. Sampath, P. I. Gouma and H. Herman, "Microstructural Characterization across Length Scales of Thermal Sprayed Ni5wt\%Al Coatings," In: B. R. Marple, Ed., Thermal Spray: Advancing the Science and Applying the Technology (ITSC 2003), ASM International, Material Park, Orlando, 5-8 May 2003, pp. 1419-1428.

[15] R. Panat, S. Zhang and K. J. Hsia, "Bond Coat Surface Rumpling in Thermal Barrier Coatings," Acta Materialia, Vol. 51, No. 1, 2003, pp. 239-249.

[16] V. K. Tolpygo and D. R. Clarke, "Surface Rumpling of a (Ni,Pt)Al Bond Coatinduced by Cyclic Oxidation," Acta Materialia, Vol. 48, No. 13, 2000, pp. 3283-3293. doi:10.1016/S1359-6454(00)00156-7 